\title{
INVESTMENT, DURATION, AND EXIT STRATEgIES FOR CORPORATE AND INDEPENDENT VENTURE CAPITAL-BACKED START-UPS
}

\author{
BING GuO \\ Universidad Carlos III de Madrid \\ Business and Administration Department \\ Calle Madrid 126, Getafe 28903, Spain \\ bing.guo@uc3m.es \\ YUN LOU \\ HEC Paris, Department of Accounting and Management Control \\ 1 Rue de La Liberation, Jouy-en-Josas \\ Paris, France \\ lou@hec.fr \\ David PÉrez-Castrillo \\ Universitat Autònoma de Barcelona and Barcelona GSE \\ Department of Economics \\ Edifici B \\ Bellaterra 08193, Barcelona, Spain \\ david.perez@uab.es
}

We propose a model of investment, duration, and exit strategies for start-ups backed by venture capital (VC) funds that accounts for the high level of uncertainty, the asymmetry of information between insiders and outsiders, and the discount rate. Our analysis predicts that start-ups backed by corporate VC funds remain for a longer period of time before exiting and receive larger investment amounts than those financed by independent VC funds. Although a longer duration leads to a higher likelihood of an exit through an acquisition, a larger investment increases the probability of an IPO exit. These predictions find strong empirical support.

\section{INTRODUCTION}

Entrepreneurs and venture capitalists make investment decisions and choose the length of their involvement in a start-up to maximize the chances of success and the value of their ventures. Looking ahead, they also develop strategies to cash in on their companies.

We thank Albert Banal-Estañol, Marco Da Rin, Gary Dushnisky, María Gutiérrez, Laurent Linnemer, Inés Macho-Stadler, Eduardo Melero, Philipp Meyer, Manuel Núñez-Nickel, Pau Olivella-Cunill, Neus Palomeras, Pedro Rey-Biel, Sara de la Rica, Pablo Ruiz-Verdú, Jo Seldeslachts, Anna Toldra-Simats, Arvis Ziedonis, two referees, a co-editor of JEMS, and participants at the MOVE workshop on venture capital, the 2011 LSE Alternative Investments Research Conference, the Symposium of Industrial Organization and Management Strategy, EARIE 2012, the Sixth Annual Conference on Innovation and Entrepreneurship at Northwestern University, and seminars at Universidad Carlos III de Madrid, CREST, GATE, Ben-Gurion University of the Negev, and University College Dublin, for their helpful suggestions. We are grateful to AGAUR, research projects ECO2009-07616, 2014SGR-142, ECO2012-31962, ECO2010-22105-C03-03, ECO2013-45864-P and INFOINNOVA (03513A), the Government of Catalonia, ICREA Academia, and the Severo Ochoa Programme for Centres of Excellence in R\&D (SEV-2011-0075) for financial support. We also thank Gary Dushnisky for sharing the VEIC-SIC Concordance with us. Pérez-Castrillo is a MOVE fellow. 
In particular, these strategies allow venture capitalists to liquidate their shares. Planning an exit strategy is as important as deciding how to start the enterprise.

There are two main exit routes for a successful start-up. The company can go through an Initial Public Offering (IPO) or it can be sold to an existing firm via an acquisition. ${ }^{1}$ Under an IPO, the venture obtains a stock market listing, which enables the company to receive additional financing for its projects and enables insiders to eventually sell their shares to the public. If the start-up is acquired, the insiders obtain immediate cash in return for their shares. Understanding the main trade-offs faced by start-ups at the exit stage is crucial because this understanding not only allows one to determine how venture capitalists and entrepreneurs divest their companies but also how the decisions are taken at the onset of the venture.

The optimal exit route for a start-up depends on multiple factors, such as the expected profitability of the venture, the level of uncertainty, the asymmetry of information between the insiders and outsiders (e.g., potential buyers and new investors), ${ }^{2}$ the possible conflicts of interest among insiders, ${ }^{3}$ the financial market conditions at the time of the exit, and the characteristics of the venture capitalists. Whether the start-up receives financing from Corporate Venture Capital (CVC) funds or only from Independent Venture Capital (IVC) funds may be of particular importance. Some of these factors are affected by the level of the partners' investment as well as their decision concerning the duration of the venture (i.e., the length of the relationship between the entrepreneur and the VCs until the exit of the start-up). That is, there is a strong link between the decisions concerning investment and duration and the exit route finally chosen by the start-up.

We build a model that encompasses three crucial decisions in the lives of startups (investment, duration, and exit) rather than focusing on other, albeit interesting, aspects that appear at particular moments in time. This modeling strategy allows us to obtain theoretical results concerning the aforementioned decisions, which we test using data from U.S. start-ups. We propose a simple model that accounts for the high level of uncertainty regarding the returns from an investment in a start-up, the existence of private information in the hands of insiders, and the discount rates of the partners in the start-ups. We choose to study a rather parsimonious model in which we abstract from possible internal conflicts among insiders and the dynamic interaction between investment and duration.

In our model, the amount of capital invested in a start-up influences the start-up's expected value. We assume that a higher investment leads to a higher expected value of the start-up. Furthermore, the decision regarding the duration of the start-up affects the market information about the probability of the venture's success. We assume that the potential value of the venture at the time of its exit will be known to every market participant. Nevertheless, insiders have more precise information about the expected profitability of a start-up because they know the probability of its success. Whether outsiders are informed of this probability depends on how long the start-up remains in the market before exiting.

1. Two other exit routes that are not as commonly used are Management Buy-out and Refinancing (or secondary sales); see Schwienbacher (2010).

2. See Cumming and MacIntosh (2003) for a discussion about the information asymmetries between sellers and the potential buyers of start-ups.

3. See, for instance, Gompers (1995); Kaplan and Strömberg (2003); De Bettignies (2008); and Macho-Stadler and Pérez-Castrillo (2010). 
We show that the ventures with a higher expected value are more likely to attempt an IPO, whereas those with a lower expected value prefer to seek an acquirer. Moreover, the likelihood of exiting through an IPO increases with the potential value of the start-up as long as that value is positive. In contrast, start-ups with a negative potential value are liquidated. We link a start-up's exit strategy with the investment decision and with the market level of information. We show that a higher investment level induces a greater likelihood of a successful exit. Of the successful exits, the higher the investment level is, the higher the likelihood of an IPO exit. Moreover, the IPO exit rate is lower if outsiders receive more precise information, that is, if the duration of the venture is longer. Finally, we analyze the optimal investment and duration decisions of the start-up. In particular, we show that both the level of investment and the duration of the venture decrease with the discount rate of the venture capital.

In the empirical part of the paper, we test our theoretical results by analyzing the differences in the investment, duration, and exit strategies of the start-ups depending on the type of the venture capital fund. We focus on the fact that CVC funds are more patient than IVC funds in realizing financial returns from their investments in startups, and we analyze how this difference influences the strategies of the start-ups. ${ }^{4}$ Our empirical results confirm the theoretical predictions: CVC-backed start-ups receive larger investment levels and have longer durations before their exit than start-ups that only receive IVC financing. Moreover, these two consequences of the presence of CVC funds in the start-ups have opposite impacts on the likelihood of an IPO exit: the larger investment level increases the likelihood of an IPO exit whereas the longer duration increases the probability of an exit though acquisition. Once these effects are considered, the type of the VC fund has no significant influence on the exit decision. ${ }^{5}$

We acknowledge that, in the empirical tests, there exists an identification problem, because start-ups are not randomly matched with different types of VC investors (i.e., CVCs vs. IVCs). To mitigate the endogeneity problem, we use both a treatment-effects model to test the effect of the VC fund type on the investment, duration, and exit strategies and an instrumental variable approach to test the exit strategy. In the first stage estimation of the treatment-effects model, we identify that the probability of a start-up receiving CVC funds, compared with only receiving IVC financing, increases if the start-up is in an industry with a higher average liquidity level, a higher average net cash flow, or if it is in a geographical area with more CVC funds compared to IVC funds. CVCs also invest more in start-ups with a higher number of patent applications. After controlling for such effects on the matching between start-ups and CVC financing, we find that our main predictions from the theoretical model are confirmed. Moreover, we construct two instrumental variables for the endogenous variable (start-ups financed by CVC funds): 5-year average working capital at industry level (to capture liquidity) and the average CVC investment as a ratio of the total investment in a geographical area. The instrumental variable estimation shows very similar results.

The main message of the paper is that the joint analyses of the major decisions taken by the start-up at several moments of its life helps us better understand how the nature of the VC fund influences these decisions. Abstracting from differences in the

4. In the next section, we discuss the nature of CVC and IVC funds and the implications of the differences between the two types of fund on their patience in terms of investments.

5. We provide additional evidence of the effect of the discount rate by also analyzing the influence of the VC fund size on the investment level, duration, and the likelihood of an IPO. The effects are similar to those induced by the presence of CVC funds, which agrees with our theory because the discount rate of a fund is likely to decrease with its size. 
strategic incentives of VCs, we highlight that the nature of the VC fund influences the level of investment and the duration of the venture. And these two decisions have a strong and opposite impact on the likelihood of the start-up exiting through an IPO or an acquisition. Therefore, the sign of the indirect effect of the nature of the VC fund on the exit decision of the start-up depends on the strength of its two indirect impacts through the investment and the duration.

\section{Corporate Venture Capital Funds}

Corporate venture capital is the direct investment of corporate funds in external start-up companies. That is, through its CVC fund a company invests, without using a third-party investment firm, in an external start-up that it does not own.

CVC appeared at the end of the Thirties in the United States and it has become one of the most widespread forms of financing for new innovating firms (Lantza et al., 2011). The number of CVC funds increased rapidly in the eighties, where many dynamic small companies performed a fundamental role for innovation in high-tech sectors. Then, large corporations questioned their expensive R\&D programs and decided to invest in innovative firms through private equity funds. In their 2008 study on a sample of the 142 largest market capitalizations of American and European technology-based companies, Lantza et al. (2011) found that $60 \%(40 \%)$ of the American (European) groups have CVC funds, with a median size of 140 (120) million dollars.

A primary advantage of CVC investments is the strategic flexibility they offer (Basu et al., 2011). In general, they involve smaller irreversible investments of organizational resources than internal R\&D and are thus easier and cheaper to restructure or exit when environmental conditions change (Folta, 1998). Moreover, the resources committed in each venture are small, which allows them to enter into very uncertain initiatives.

Unlike traditional IVC funds, which are limited partnerships, CVC funds are subsidiaries of corporations (Chemmanur et al., 2013). Several differences exist between the two types of funds.

First, whereas the sole objective of an IVC fund is to actualize a financial return on capital, CVC programs also care about strategic returns, such as the development of new, related business (see Sykes, 1990; Yost and Devlin, 1993; Dushnitsky and Lenox, 2006; Hellmann et al., 2008). CVC operations allow companies to gain access to external, entrepreneurial innovations. They also allow them to identify emerging markets and potential applications of their own products. The strategic objectives can explain why corporations choose to hire their own general partners as opposed to outsourcing the job and simply taking the role of a limited partner of some IVC funds. Through the CVC, a corporation can have a direct eye on any start-ups.

Second, because of the presence of the corporate parent, CVC funds can provide more industry-related knowledge and support to start-ups than IVC funds, capitalizing on corporate resources (Riyanto and Schwienbacher, 2006; Chemmanur et al., 2013).

Third, the structure of managers' payments is quite different for CVC and IVC funds. IVC fund managers typically receive (in addition to 1 to $2 \%$ fixed fees based on the size of the fund) $20 \%$ of the profits of the fund, which can result in enormous salaries and bonuses if the fund successfully exits via an IPO or acquisition. To maintain a level fee structure across different units of the overall corporate enterprise, CVC funds typically do not enjoy such performance fees. Their managers write contracts that more often focus on downside protection than upside potential, relative to limited partnership venture capital funds (Meyer and Mathonet, 2005; Cumming and Johan, 2009). 
Fourth, CVC managers are likely to be less concerned with fast financial returns from their portfolio firms than IVC managers (Manso, 2011; Chemmanur et al., 2013). The ability of IVC managers to raise additional funds depends on their reputations, which are influenced by their history of success (Gompers, 1995; Dushnitsky and Shapira, 2010; Crain, 2013). As Meyer and Mathonet (2005) report, an IVC managing team without a reputation has a significant incentive to quickly establish a "track record" and could therefore make too early exits. ${ }^{6}$

Finally, CVC investors have more unused resources, such as technology and marketing resources, than IVC investors (Sahaym et al., 2010; Basu et al., 2011; Da Gbadji et al., 2011).

The aforementioned differences between the two types of funds suggest that IVC managers are more concerned with quick exits than CVC managers. Above all, CVC managers are less anxious than IVC managers about financial returns, particularly with fast financial returns. In our empirical sections, we relate the fact that a CVC is willing to stay longer in the start-up before realizing returns than an IVC to a lower discount rate and we analyze the consequences of this difference in the investment, duration, and exit decisions.

The theoretical and empirical academic research on venture capital and on the strategies followed by start-ups is growing. In particular, some recent papers analyze the influence the type of start-up has on the optimal exit pathway. One of the key results is that high-quality start-up companies go public while low-quality companies are acquired, which provides an explanation for the IPO valuation premium puzzle (see Bayar and Chemmanur, 2011, for a theoretical analysis and Bayar and Chemmanur, 2012, for an empirical test). Other characteristics of a start-up are also important for the choice of the exit route (see Brau et al., 2003; Poulsen and Stegemoller, 2008; Bayar and Chemmanur, 2011, 2012; Chemmanur et al., 2012). Start-ups are more likely to choose IPO instead of acquisition if they are more established companies with a viable business model and greater growth opportunities. The probability of an IPO is also higher for start-ups in high-tech industries, and in industries characterized by low concentration and where private benefits of control are larger. Finally, venture-backed start-ups are more likely to go public compared to non-venture-backed firms.

However, the impact of the type of VC fund (i.e., CVC funds vs. IVC funds) on the investment, on the exit and, in particular, on the duration strategy of start-ups has not received much attention in the literature. ${ }^{7}$ We briefly discuss the contributions that are most relevant to our paper.

With regard to the influence of VC fund characteristics on the level of investment for a start-up, the theoretical model of Hellmann (2002) and the empirical analyses of Gompers and Lerner (2000) and Masulis and Nahata (2009) find, as our paper, that startups receive higher investment amounts from CVC funds than from IVC funds. Besides investment, CVCs help their portfolio companies create value in several ways. Because of their greater tolerance for failure and better knowledge of technology, CVCs invest in younger and riskier companies and achieve a higher degree of innovation (Chemmanur and Loutskina, 2008; Chemmanur et al., 2013). Also, when the start-ups have a strategic fit with the parent corporation of the CVCs, they receive higher takeover premiums when they become acquisition targets (Ivanov and Xie, 2010).

6. Funds that have performed well in the past tend to be oversubscribed. When a fund with a track record raises a new fund, investors in previous funds quickly oversubscribe it (Meyer and Mathonet, 2005).

7. See Da Rin et al. (forthcoming), for a survey of the academic work on venture capital and, in particular, for a review of the papers that examine the structures and strategies of VC funds. 
Concerning the choice of an exit route (i.e., IPO vs. acquisition), most papers suggest that because of the CVC funds' strategic returns, CVC-backed start-ups are more likely to exit through an acquisition than IVC-backed start-ups. This argument has been put forward by theoretical studies (Hellmann, 2002; Riyanto and Schwienbacher, 2006) and has received empirical support from a study using a European dataset (Cumming, 2008). Based on survey evidence, Siegel et al. (1988) and Sykes (1990) also find that the percentage of acquired CVC-backed start-ups is higher than the percentage of acquired IVC-backed ventures. However, this result is challenged by Gompers and Lerner (2000) and Chemmanur and Loutskina (2008), who find that CVC-backed start-ups exit more frequently through the IPO market than IVC-backed start-ups do. Moreover, few startups appear to be acquired by the parent companies of the CVC funds that financed these ventures. In the ThomsonOne and the Securities Data Company Global New Issues databases that we use, only $5 \%$ of the start-ups with CVC financing that exit via acquisitions are bought by the parent company of the CVC fund. Maula and Murray (2001) find a similar result.

Our paper contributes to a better understanding of the impact of the nature of the VC on the decisions taken by start-ups. Instead of focusing directly on a startup's decision concerning exit, we look at the direct influence of the nature of the VC on the level of investment and on the duration and identify the impact of these two channels on the exit decision. Our theoretical and empirical analyses confirm that the level and the duration of investment are positively affected by the presence of CVCs. Moreover, we show that investment and duration have opposite influences on the exit decision: a higher investment and a shorter duration increase the likelihood of an IPO exit. This novel strategy of analysis allows us, in particular, to provide an explanation for the disagreement in the existing empirical literature regarding the exit choices made by CVC- and IVC-backed start-ups. Indeed, if the indirect effect on the exit of the presence of CVCs through the investment decision is stronger than that through the duration decision, then CVC-backed start-ups are more likely to exit through an IPO (as in Gompers and Lerner, 2000, and Chemmanur and Loutskina, 2008) whereas if the indirect effect through the duration decision is stronger, then the likelihood of an acquisition exit is higher for CVC-backed start-ups (as in Siegel et al., 1988, Sykes, 1990, and Cumming, 2008). Finally, to mitigate the common identification problem in the CVC financing literature (i.e., start-ups and VC funds are not matched randomly), we propose some possible effects on the match between start-ups and VC fund types and construct two instrumental variables.

\section{THE MODEL}

We propose a model to analyze the optimal investment and duration decisions, as well as the exit strategy of a start-up $(S)$ backed by a venture capital fund. We assume that the entry by the fund in the start-up has already taken place, that is, we do not model the entry decision by the venture capital fund. ${ }^{8}$ As mentioned in the Introduction, we abstract from possible internal conflicts among venture capitalists and managers/founders of the start-up. The decisions made by the start-up at any stage aim to maximize its expected discounted profits, that is, expected revenue minus costs (including investment costs). ${ }^{9}$

8. We will discuss issues related to the possible endogeneity of the entry decision by the venture capital fund in the empirical part of the paper, especially in Section 9.

9. In Section 6, we discuss the implications of the nature of the VC on the objective function of the start-up. 


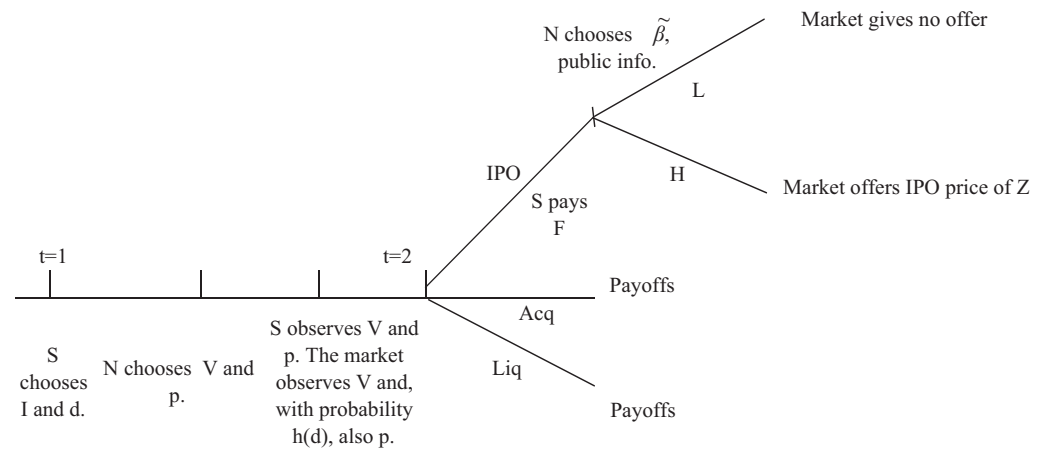

FIGURE 1. THE TIMELINE

This figure shows the timeline of the game. The start-up chooses an investment and a duration strategy at the first stage, and determines an exit strategy at the second stage.

In our model, the start-up takes decisions at two moments: at the beginning of the venture $(t=1)$ and at the exit of the venture $(t=2)$. We now describe the model, that is, the sequence of events and the consequences of the start-up's decisions, and we identify and discuss the main assumptions. Figure 1 captures the timeline.

At $t=1$, the start-up decides on the level of investment $I$ and its duration $d$. Although we acknowledge that the financing of a start-up is a dynamic process where, at each period, the information on the current development of the start-up is used to decide on the next investment, we simplify this process and assume that the total investment amount and the duration are fully determined at the beginning of the model. ${ }^{10}$

We assume that the level of the investment I has a positive influence on the expected value of the start-up, which is $p V$. We denote by $V$ the potential net value of the venture, that is, the revenues that the start-up can generate, once we subtract the additional expenses required to continue with the firm (the variable $V$ can be positive or negative), and we denote by $p$ the probability of success, that is, the probability of realizing $V$. We take the view that the investment has a positive impact on crucial aspects of the start-up, such as the number and quality of the patents, the product quality, and the size of the network of input suppliers and customers. Better funding allows the hiring of more qualified managers and workers, the buying of better equipment, and more in-depth market studies to be conducted, etc. Therefore, the higher the investment level, the larger the expected total revenue and/or the probability of survival. ${ }^{11}$

Our second main assumption is that the level of the durationd influences the information accessed at the time of exit by potential acquirers about the expected value of the start-up. Startup owners and managers are reluctant to give potential acquirers too much access to information and to the key engineers and other valuable members of the company before the board determines an acquisition event because it would place the entire company

10. Therefore, our model does not account for some dynamic aspects of the start-up that are not relevant for our purposes. Additionally, with stage financing, the uncertainty is somewhat but not completely mitigated. The simplified one-period model that we use to describe the investment and duration decisions is just one extreme case in which more uncertainty exists at the time when the decisions are made. It allows the consideration of investment, duration, and exiting decisions in a simple two-period model.

11. A similar hypothesis can be found, for instance, in Bergemann and Hege (1998), Hong et al. (2013), and Conti et al. (2013). 
at risk. ${ }^{12}$ As a consequence, there will be asymmetric information about the value of the start-up at the time of its exit. However, as argued, for example, by Felix et al. (2014) the degree of asymmetry of information between insiders and potential acquirers is expected to decrease over time.

We model the differential effect of investment and duration in a simple way. We assume that $I$ determines the distribution of the potential value of the start-up $V$ whereas $d$ affects the information that flows to the acquisition market about $p .{ }^{13}$ A larger investment $I$ shifts the distribution of $V$ to the right: higher investment leads to higher expected revenues $p V$. For the sake of simplicity, we assume that ex ante $V$ is uniformly distributed over the interval $[f(I), \widehat{V}+f(I)]$, where $f(I)$ is an increasing function of $I$. Concerning the probability $p$ of success (i.e., the probability of realizing $V$ ), we assume that $p$ is uniformly distributed ex ante over the interval $[0,1]$.

After investment has been made in the start-up and before the exit decision, the uncertainty concerning $V$ and $p$ is resolved (that is, "Nature" chooses $V$ and $p$ ). All of the market participants can observe some of the information, but the insiders acquire more precise information on the expected quality of the project than the outsiders do. In particular, we assume that both the start-up and the outside market can observe the realization of the value of $V$. However, although the start-up also learns $p$, the potential acquirers only learn $p$ with probability $h(d)$, which increases as the duration $d$ increases. Therefore, although insiders and outsiders get information about the expected value of the project $p V$, the insiders may retain some private information about it.

At $t=2$, the start-up makes the exit decision. It has three possible exit routes: liquidation, an acquisition, or an IPO.

- The liquidation value of the start-up is always 0 .

- The deal price that the start-up obtains if it decides to seek an acquirer is the issue of a negotiation between the two parties. We assume that the acquirer has bargaining power. As discussed, for example, by Zingales (1995) and Bayar and Chemmanur (2011), the market of potential acquirers is not perfectly competitive and acquirers can be expected to have considerable bargaining power. They can pressure incumbents on pricing concessions. Therefore, the deal price depends on the respective bargaining power of the start-up and the acquirer. It also depends on the information obtained by the acquirer. We assume that, in the Nash bargaining, the start-up obtains a share $m$ of the venture's expected value from the acquirer. That is, for simplicity, we consider that the profits of the outside option for both the start-up and acquirer are 0 and that the bargaining power of the start-up is $m$ (and that of the acquirer is $1-m$ ). ${ }^{14}$

- In an IPO, shares of the start-up are sold to public investors, whose bargaining power is expected to be very small (see Zingales, 1995, and Bayar and Chemmanur, 2011). Therefore, we assume that the IPO market is competitive. On the other hand, the IPO

12. See, for example, the discussion "Start-up dilemma: to sell or not to sell" by Roger Ehrenberg, founder and Managing Partner of IA Ventures, in informationarbitrage.com.

13. Expressing the expected value of the venture as a product of two terms, $p$ and $V$, allows us to separate the effects of $I$ and $d$ in a simple manner. As indicated above, the crucial assumptions are that $I$ mainly influences the expected value whereas $d$ mainly affects the level of information. Alternative modelizations of these effects would lead to similar results. For example, we can assume that the investment has a positive effect of $p$ and the duration decreases the asymmetry of information concerning $V$ without affecting the results of the paper.

14. The outside option for both agents is typically not zero. In reality, if negotiations between the start-up and the (potential) acquirer were to fail, the start-up could seek another buyer and the previous potential acquirer could invest the resources in another venture. The assumption that the outside option gives zero profits to both participants is made for simplicity. The relevant hypothesis is that both agents obtain a share of the surplus. 
process is costly. Indeed, the valuation of the start-up in an IPO depends on the result of a thorough analysis concerning all possible aspects of the start-up. An IPO is a process that requires underwriters, attorneys, accountants, financial printers, and financial analysts. They exercise due diligence in aspects such as corporate valuation, customers' assessment, and market prospects, as well as on legal, financial, and intellectual property matters. We use $F>0$ to denote the substantial out-of-pocket expense that is involved in preparing an IPO. The process generates a public signal about the profitability of the venture that we denote by $\widetilde{\beta}, \widetilde{\beta} \in\{H, L\}$. We assume a very simple structure for the signal: a realization of $\widetilde{\beta}=H$ represents a situation where the process has been able to verify that the start-up will be a success, whereas $\widetilde{\beta}=L$ represents a situation where the IPO process has not been able to make the verification. The probability of observing $\widetilde{\beta}=H$ depends on the actual probability of success $p$ and we assume that it is equal to $\beta p$, with $\beta>0$. If the realization of the signal is $H$, the competitive market sets a price $Z$ for the IPO that is equal to the start-up's expected value. If the start-up accepts the price, then a successful IPO is executed. If the signal is $L$, no offer is issued. ${ }^{15}$

We make assumptions regarding the functions $f(I)$ and $h(d)$ to ensure that the three exit routes are possible. We assume that $\widehat{V}+f(0)>F /(\beta-m)$ and that $f(I)$ is concave enough (specifically, $\lim _{I \rightarrow \infty} f(I) \leq 0$ ). Also, the screening is informative enough: $\beta>$ $m$. Finally, the venture makes interior choices of $I$ and $d$ if $\lim _{I \rightarrow 0} f^{\prime}(0)=\lim _{d \rightarrow 0} h^{\prime}(0)=$ $\infty$ and $h(d)$ is concave enough. ${ }^{16}$

We solve the model through backward induction, realizing that asymmetric information may exist among the participants. Therefore, we use sequential equilibrium as the solution concept because it combines subgame perfection ideas with Bayesian updating.

\section{The analysis of the Optimal Exit Strategy}

In this section, we start at $t=2$. At this stage, the potential value of the venture $V$ is realized and observed by all of the participants. Moreover, the start-up receives a private signal concerning the probability of success $p$. The potential acquirer may or may not have this information $p$ (this information is accessed with probability $h(d)$ ). We study the optimal exit strategy in both situations.

\subsection{OPTIMAL EXIT STRATEgY WITH INFORMED ACQUIRERS}

It follows immediately from the description of the three exit routes that the firm is liquidated if $p V \leq 0$, in which case the value of the start-up is $0 .{ }^{17}$ We now compare the start-up's expected profits under the other two exit strategies when $p V>0$.

15. We assume that a start-up that receives a low signal does not receive any offers. We make this assumption for the sake of simplicity. For those start-ups that receive a signal $L$, the situation is often similar to the market for lemons in Akerlof's (1970) model; that is, taking into account the set of start-ups that accept the offer, there is no price under which market profits are non-negative (for an analysis, see Guo, 2010).

16. If $\beta<m$, then the IPO route is never chosen. If $\hat{V}+f(0)<F /(\beta-m)$, then those start-ups with low investment levels never take certain exit routes. If $\lim _{I \rightarrow \infty} f(I)>0$, then those start-ups with high investment levels never undergo liquidation. However, our qualitative results would remain the same, despite the changes in the hypotheses. Similarly, if $\lim _{I \rightarrow 0} f^{\prime}(0)=\lim _{d \rightarrow 0} h^{\prime}(0)<\infty$, then the optimal decision concerning $I$ and/or $d$ may be the corner solution $I=0$ and/or $d=0$, which would complicate the analysis without adding new insights.

17. We use the convention that a start-up that is indifferent between being liquidated or not chooses liquidation. Similarly, a start-up that is indifferent between going to an IPO and looking for an acquirer at $t=2$ goes to an IPO. 
If the start-up negotiates with an acquirer that knows $p$, the expected value of the start-up $p V$ is common knowledge and the bargaining between start-up and acquirer will produce a deal price of $m p V .{ }^{18}$ If the start-up goes through an IPO, it pays $F$ and receives a valuation that depends on the realization of the signal $\widetilde{\beta}$. If $\widetilde{\beta}=L$, which happens with a probability of $(1-\beta p)$, the start-up does not receive any offers. If the realization is $\widetilde{\beta}=H$, then the competitive investors' market offers $Z=V$, which the start-up accepts.

Therefore, the start-up obtains higher expected profits by issuing an IPO rather than negotiating with an acquirer if and only if

$\beta p V-F \geq m p V$.

Proposition 1, whose proof follows the previous discussion, describes the optimal exit strategy in this case.

Proposition 1: Consider a start-up characterized by $(V, p)$ in a situation where the potential acquirers have learned $p$. The start-up's optimal exit strategy is as follows:

1. If $p V \leq 0$, the start-up is liquidated and realizes the payoff $U_{o}(V, p)=0$.

2. If $p V \in(0, F /(\beta-m))$, the start-up goes to the acquisition market. It obtains a deal value $U_{0}(V, p)=m p V$.

3. If $p V \geq F /(\beta-m)$, the start-up invests $F$ and goes to the IPO market. Moreover,

(a) If the public signal is $H$, then the start-up receives an offer $Z=V$ from the IPO market and accepts it;

(b) If the public signal is $L$, then the start-up does not receive any offer from the IPO market.

Therefore, in this case, the start-up's expected payoff is $U_{0}(V, p)=\beta p V-F$.

The basic trade-off between an IPO and an acquisition is that although the IPO process is costly, it also allows the owners of profitable ventures which receive a high signal to realize a larger share of the ventures' value. Start-ups with a sufficiently high probability of success are ready to pay the cost of the process.

We notice that the higher the expected value $p V$, the more willing the start-up is to go to the IPO market. Moreover, an efficient IPO process, reflected by a low-cost $F$ and a powerful screening capability $\beta$, and a higher bargaining power $m$ increase the attractiveness of an IPO exit.

\subsection{OPTIMAL EXIT STRATEgy WITH UNINFORMED ACQUIRERS}

If the potential acquirer does not know the value of $p$, the optimal strategy of a start-up searching for an exit can only be analyzed by finding the Bayesian Nash equilibrium of a game where one of the parties (the start-up) has private information relevant to the relationship (the probability of success).

In this situation, as before, the start-up is liquidated if and only if $p V \leq 0$. Concerning the start-ups with $p V>0$, one subset of "types" $p$ seeks an acquirer whereas the complementary subset issues an IPO. For a start-up going to an IPO, on the one hand, the IPO offer is $Z=V$ if the signal is $\widetilde{\beta}=H$, and the start-up accepts the offer. On the other hand, there will be no offer if the signal is $\widetilde{\beta}=L$.

18. See, for instance, Osborne and Rubinstein (1990) and Muthoo (2002) for bargaining protocols that lead to this payoff for the "seller," that is, for the start-up. 
We now analyze the bargaining situation between a start-up (whose type belongs to the subset of types that seek an acquirer) and the acquirer. The latter cannot observe the type of the start-up. Additionally, from the point of view of the negotiation, all the types are indistinguishable (there is no room for signaling, as the cost of the signal would be the same for every possible type). Therefore, the negotiation between the acquirer and the start-up is similar to another one where the acquirer faces one start-up whose (known) value corresponds to the expected value of the subset of types that, at equilibrium, seek an acquirer. And the deal price will be the share $m$ of that expected value. $^{19}$

Given that the equilibrium deal price does not depend on the actual probability $p$ of the start-up, the difference between the potential profits from an IPO and those from an acquisition increases with the value of $p V$. Therefore, there is a cut-off equilibrium value $p^{*}(V)$ such that the start-up goes to an IPO if $p \geq p^{*}(V)$ whereas it seeks an acquirer if $p<p^{*}(V)$. Given the start-up equilibrium behavior, the expected value of $p V$ of the start-ups that seek an acquirer is $p^{*}(V) V / 2$ and the deal price is $m p^{*}(V) V / 2$.

A start-up with the potential value $V$ and whose probability of success is equal to $p^{*}(V)$ must be indifferent with regard to whether it goes to an IPO or looks for an acquirer. Therefore, $p^{*}(V)$ is characterized by

$\beta p^{*}(V) V-F=m p^{*}(V) V / 2$,

when the solution to the equation is lower than 1 and $p^{*}(V)=1$ otherwise. Proposition 2 describes the equilibrium behavior of start-ups in a situation where outsiders do not know the value of $p$.

Proposition 2: Consider a start-up characterized by $(V, p)$ in a situation where the potential acquirers do not know the value of $p$. The start-up's equilibrium exit strategy is as follows:

1. If $p V \leq 0$, the start-up is liquidated. It realizes the payoff $U_{o o}(V, p)=0$.

2. If $p V \in(0, F /(\beta-m / 2))$, the start-up goes to the acquisition market. It obtains a deal value $U_{o o}(V, p)=\frac{1}{2} m V$ if $V \leq F /(\beta-m / 2)$ and $U_{o o}(V, p)=m F /[2(\beta-m / 2)]$ if $V>$ $F /(\beta-m / 2)$.

3. If $p V \geq F /(\beta-m / 2)$, the start-up invests $F$ and goes to the IPO market. Moreover,

(a) If the public signal is $H$, then the start-up receives an offer $Z=V$ from the IPO market and accepts it;

(b) If the public signal is $L$, then the start-up does not receive any offer from the IPO market.

Therefore, in this case, $U_{o o}(V, p)=\beta p V-F$.

\section{THE IMPACT OF INVESTMENT AND DURATION ON THE LIKELIHOOD OF AN IPO AND ON THE RATE OF SUCCESS}

We now analyze how a start-up's optimal exit strategy is influenced by its investment and duration decisions.

19. To be more precise, denote $W$ the expected net value of the subset of start-ups that, at equilibrium, go to the acquisition market. Consider a bargaining protocol (a game of alternating offers) between an acquirer and a start-up whose probability is known by the acquirer and whose net value is $W$. Suppose that the subgame perfect equilibrium strategies in the bargaining protocol lead to a deal price of $m W$ (this may happen as the time between offers converges to zero, see Osborne and Rubinstein, 1990, and Muthoo, 2002). Then, the same strategies constitute a subgame perfect equilibrium in the game between an acquirer and a start-up whose probability $p$ is unknown to the acquirer and whose expected net value is $W$. In this equilibrium, the start-up follows the same strategy independent of its "type." 


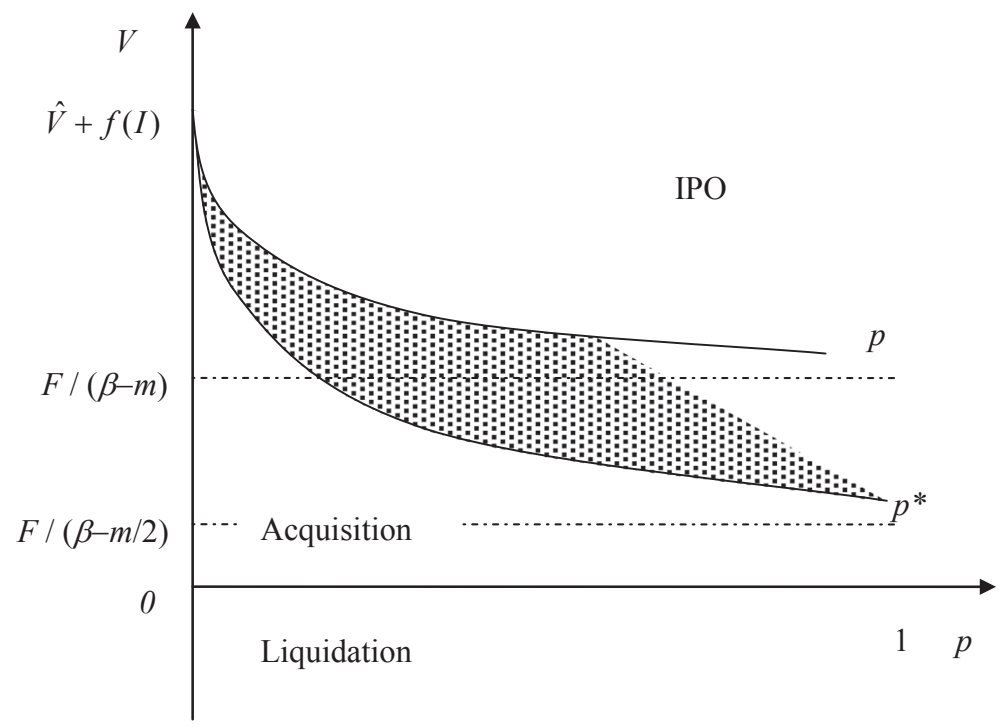

\section{FIGURE 2. THE OPTIMAL EXIT STRATEGY}

This figure depicts the optimal exit strategy. For high values of $p$ and $V$, an IPO is the optimal exit route. Going to the acquisition market is the optimal start-up strategy for low values of $p$ and $V$. In the shadow region, start-ups turn to an IPO if the outsiders have not learned the value of $p$. However, start-ups prefer to go to the acquisition market if outsiders do know the value of $p$.

A higher investment level implies a shift in the distribution of $V$ toward higher values. As shown in Propositions 1 and 2 (see also Figure 2), the higher the value $V$ is, the more likely the exit is to occur through an IPO rather than through an acquisition, regardless of whether the potential acquirers know the value of $p$. Therefore, a higher investment level should imply a higher IPO rate among successful cases. It should also lead to a greater likelihood of a successful exit. Proposition 3 presents these two results.

\section{PROPOSITION 3:}

1. The likelihood of an IPO among successful exits increases with the investment I.

2. The rate of successful exits increases with the investment I.

A longer duration indicates that the market has more precise information about the probability of the start-up. In our model, this increased availability of information is reflected by a higher likelihood that the acquisition market knows the probability of success $p$. The next proposition investigates whether an IPO exit is more likely with informed or uninformed acquirers. The proof of the proposition is derived from equations (1) and (2).

PROPOSITION 4: The probability of issuing an IPO is higher if the potential acquirers have not learned the value of $p$ than if they have learned the value of $p$.

Figure 2 explains Proposition 4 and depicts the optimal exit strategy highlighted in Propositions 1 and 2. For high-value start-ups, that is, for high levels of $p V$, an IPO is the optimal exit route, regardless of the information known by the potential acquirers. Similarly, going to the acquisition market is always the optimal start-up strategy for low 
but positive values of $p V$. In the intermediate (shadow) region of Figure 2, start-ups turn to an IPO if the outsiders have not learned the value of $p$. However, start-ups prefer to go to the acquisition market if outsiders do know the value of $p$.

The intuition for the existence of the intermediate region in Figure 2 is as follows. When it chooses the best exit, a start-up trades off the possibility of a high IPO valuation, at a cost, versus the deal price obtained from an acquirer. Both the IPO valuation and the IPO cost are independent of the acquirer's information, but the deal price is not. If the acquirer observes the true value of $p$, the deal depends on $p V$. However, if it does not observe the true probability of success, the deal depends on the expected value of the start-up, which is independent of the true value of $p$. Hence, the deal is a relatively good one for low-valued start-ups whereas it is a relatively bad one for high-value start-ups. A start-up that is indifferent between the two exit routes when information about $p$ is public (a high-value start-up) is strictly better-off issuing an IPO if the acquirer does not know $p$. The same holds for start-ups whose value is somewhat lower. As a consequence, an uninformed acquisition market is more likely to promote IPO exits.

Longer durations cause more information about $p$ to become available to outsiders. According to Proposition 4, this relationship implies, ceteris paribus, a reduction in the likelihood of an IPO exit. We state this argument in the following corollary:

COROLlaRY 1: The likelihood of an IPO among successful exits decreases as the duration d increases.

We note that, according to our model, the duration has no effect on the level of $V$. Therefore, the rate of successful exits is not influenced by the duration $d$.

\section{INVESTMENT AND DURATION DECISIONS}

In this section, we address the optimal initial decisions made by the start-up at $t=1$. The analysis presented in Section 3 allows us to compute the expected income $U_{o}(V, p)$ or $U_{o o}(V, p)$ of a start-up whose potential, publicly known value is $V$ and whose probability of success is $p$, depending on the degree of information known by the outsiders. We now calculate the expected profits for a given duration $d$ and a given investment $I$, which is denoted as $U(d, I)$. Performing the calculation requires us to take the expectation of the expected income over the possible values of $V$ (whose distribution function $\Gamma(V ; I)$ depends on $I$ and $p$ ):

$$
\begin{aligned}
U(d, I) & =e^{-r d} \int_{V} \int_{p}\left[h(d) U_{o}(V, p)+[1-h(d)] U_{o o}(V, p)\right] d p d \Gamma(V ; I)-I \\
& =e^{-r d}\left[h(d) E U_{o}(I)+(1-h(d)) E U_{o o}(I)\right]-I,
\end{aligned}
$$

where we denote

$$
\begin{aligned}
& E U_{o}(I)=\int_{V} \int_{p} U_{o}(V, p) d p d \Gamma(V ; I), \\
& E U_{o o}(I)=\int_{V} \int_{p} U_{o o}(V, p) d p d \Gamma(V ; I) .
\end{aligned}
$$

We can interpret $E U_{0}(I)$ as the expected profits at the exit time of a start-up that has invested $I$ at $t=0$ and whose realized probability $p$ is always known by its potential acquirers. Similarly, $E U_{o o}(I)$ is the start-up's expected profits if the realization value of $p$ is unknown to outsiders. $h(d)$, the probability that the information is known by the 
potential acquirers, increases with the duration. Moreover, the longer the duration $d$ is, the lower the expected profits at $t=0$ because of discounting.

Lemma 1 shows that $E U_{o}(I)$ is always higher than $E U_{o o}(I)$. That is, the start-up's expected profits are higher when the potential acquirers learn $p$ than when they do not. Although interesting by itself, this result is particularly useful in the analysis of the optimal duration and the investment decisions.

LEMMA 1: $E U_{0}(I)>E U_{o o}(I)$ for every $I>0$.

The asymmetry of information between start-ups and potential acquirers makes it more profitable for some ventures (i.e., those whose probability of success lies in the interval $\left.\left(p^{*}(V), p(V)\right)\right)$ to go to the IPO market, though they would obtain a better deal in the acquisition market if the information were symmetric. Therefore, in expectation, the start-up's profits are higher if information about $p$ reaches the potential acquirers (i.e., $\left.E U_{o}(I) \geq E U_{o o}(I)\right)$.

The optimal duration and investment decisions $\left(d^{*}, I^{*}\right)$ are interior. Therefore, they satisfy the first-order conditions $\frac{\partial U}{\partial d}\left(d^{*}, I^{*}\right)=\frac{\partial U}{\partial I}\left(d^{*}, I^{*}\right)=0$. In Proposition 6, we examine the effect of the discount rate $r$ on $\left(d^{*}, I^{*}\right)$.

Proposition 5: The optimal duration $d^{*}$ and investment $I^{*}$ decrease as the discount rate $r$ increases.

Proposition 5 is intuitive. Keeping the level of investment constant, a longer duration means a higher income because of the better information by the acquirers (see Lemma 1) but at a latter moment. Therefore, the optimal duration and the discount rate should go in opposite directions. Similarly, keeping the duration constant, the optimal investment level should decrease with the cost of the money, hence, with the interest rate. Therefore, if the start-up cares less about the future, it invests less in the venture and for a shorter period of time.

The proposition also allows us to discuss the (indirect) effect of $r$ on the likelihood of an IPO exit. A lower interest rate $r$ implies both a higher investment level and a longer duration which, according to Proposition 3.1 and Corollary 1, have opposite impacts on the likelihood of an IPO exit. On the one hand, a larger investment leads to more exits through IPOs. On the other hand, a longer duration implies a better-informed potential acquirer, which leads to more acquisitions.

\section{CVC-VERSUS IVC-BACKED START-UPS: EMPIRICAL IMPLICATIONS FROM THE THEORETICAL MODEL}

The analysis presented in the previous sections highlights the direct effects of the discount rate on the investment and duration decisions and its indirect effect on the likelihood of the different exit routes. In this section, we link these results with the discussion on the differences between the start-ups that receive investments from CVC funds and the start-ups that receive only IVC funding.

Decisions on a start-up depend on the objectives of the managers, founders, and investors. As we have already mentioned, in this paper we abstract from the conflicts of interest that may arise because of differences in objectives among managers/founders on one side and investors on the other side. If we focus on the "discount rate" that the start-up uses to take its decisions, the main factor of influence is the discount rate applied by the investors. Then, we argue that a start-up that receives CVC financing uses a lower discount rate than a start-up that receives only IVC financing because, as discussed in 
Section 2, CVC funds are typically less compelled to recover their investments early in the process (Manso, 2011; Chemmanur et al., 2013).

Based on the previous discussions, we associate a lower discount rate to the startups that receive CVC funding. We use our theoretical results to propose empirical hypotheses concerning the differences between CVC- and IVC-backed start-ups with respect to investment amount, duration before exit, exit strategy, and success rate.

First, Proposition 5 shows that the start-ups with lower discount rates choose higher investment levels. Therefore, we should observe higher investments in CVCbacked start-ups than in IVC-backed start-ups. We state this empirical implication in the following hypothesis.

Hypothesis 1. CVC-backed start-ups receive higher investment amounts than IVC-backed start-ups.

Second, Proposition 5 also implies that CVC-backed start-ups (having lower discount rates) choose to stay longer before they exit. This argument is reflected in Hypothesis 2.

Hypothesis 2. CVC-backed start-ups have longer durations than IVC-backed start-ups.

Third, our theoretical model shows that the characteristics of VC funds indirectly impact the exit strategies of start-ups. As previously mentioned, CVC-backed start-ups invest more in their projects than those backed by IVC financing. The model predicts that a higher investment level increases the probability of an IPO exit (see Proposition 3.1). Furthermore, a start-up with CVC backing also stays longer, which makes it less likely to exit via an IPO, according to Corollary 1 . We test the previous theoretical results using Hypothesis 3.

Hypothesis 3a. The investment amount has a positive effect on the probability of an IPO exit. Hypothesis $3 \mathrm{~b}$. The duration of a start-up before it exits has a negative effect on the probability of an IPO exit.

Fourth, higher investments imply higher rates of successful exits (see Proposition 3.2). Hypothesis 4 states this implication from our theoretical model.

Hypothesis 4. The investment amount has a positive effect on the probability of a successful exit.

\section{Data AND MEAsures}

We obtain the venture capital data from the ThomsonOne private equity database. This database contains detailed information regarding the characteristics of U.S. start-ups and their venture capital investors, such as exit routes (IPO vs. acquisition), exit dates, type of venture capital funds (CVC vs. IVC), investment amount, fund size, etc. ${ }^{20}$ To make sure that we get correct exit information, we obtain the list of IPO exits and acquisition exits from the Securities Data Company (SDC) Global New Issues Database.

20. In ThomsonOne private equity database, there are other exit routes besides IPO and acquisition, such as Management Buy-Out, which are dropped in our study. They account for $7 \%$ of all successful cases. In order to eliminate the possibility that the exit routes dropped in the data are driven by VC firms' characteristics (CVC vs. IVC), we carry out a univariate comparison. The evidence shows that the probability of exiting by other methods, besides IPO and acquisition, is not significantly different for CVC-backed start-ups and IVC-backed start-ups (i.e., the difference is around $1 \%$ and it is not statistically significant). 
We then merge the IPO list and the acquisition list from SDC with the exit information from ThomsonOne. ${ }^{21}$ We only keep the start-ups that have exit information (IPO or acquisition) in both databases. If a start-up has different exit information (i.e., different IPO date, different effective date or different IPO price, etc.) from the two databases, we use the information from the SDC New Issues Database.

Furthermore, we obtain patent information of start-ups from the NBER Patent Citation database (Hall et al., 2001). The database provides detailed information on patents granted by the United States Patent and Trademark Office (USPTO) from 1976 to 2006, such as patent application year, granted year, citing and cited patents, etc. Because the NBER patent database only covers patents that were granted, the coverage of the patents filed in the latest years is partial. Hence, our final dataset excludes start-ups with a first investment year after 2004. We manually match the patenting database with the ThomsonOne private equity database based on both the start-up name and patent application year. ${ }^{22}$ From the patenting database, we use the number of patents applied (or the number of citations received by all the applied patents) by a start-up before securing any VC investments, as a measure of the start-up quality/innovativeness. The NBER patent database has two types of truncation problems. First, the lag between patent applications and patent grants is on average two years but the variation is large. To mitigate this truncation problem, we use the number of patents applied instead of the number of patents granted as the proxy for innovativeness, excluding start-ups with a first investment year after 2004. Second, the patent database ends in 2006. Then, more recent patents have less time to accumulate citations than patents created in earlier years. To deal with this problem, we follow Hall et al. (2001) and Atanassov (2013) and we use the "time-technology class fixed effect" method. We scale the citations by the average number of citations for all patents issued in the same technology class in the same year.

We also gather information from Compustat for financial data and Morgan Stanley Capital International (MSCI) for the stock market information.

After merging the five data resources, we obtain our final sample, which consists of 4,311 successful U.S. start-ups with first investment year from 1980 to $2004 .{ }^{23}$ The final sample is a cross-sectional dataset at start-up level. ${ }^{24}$

The main independent variable of interest assesses whether a start-up receives financing from CVC funds. To define whether a VC fund is CVC or IVC, we start from the information of the type of investors provided by ThomsonOne database. Using

21. We merge these two databases because of some authors' concern about the accuracy of the exit information in ThomsonOne (see, for instance, Da Rin et al., 2013). We also run all the regressions in this paper only with the exit information from ThomsonOne, and the results are very similar.

22. To merge the ThomsonOne data with the patent database, we manually check the names of the startups, one by one, in both databases. This is because different databases use slightly different names for the same company. By checking the names manually, we merge company names such as "3 Dimensional Pharm Inc" from the patent database with "3-Dimensional Pharmaceuticals, Inc." If firms have similar names from the two database but we are not sure whether they are the same firms, we double check the firms history and address using Google and LexisNexis.

23. Our theoretical model predicts that CVC-backed start-ups have higher investment levels and stay longer before exiting. This model considers both successful exits (IPOs and acquisitions) and unsuccessful exits (liquidation). However, we obtain the same results when we only consider the successful exits in the theoretical model. In Subsection 9.5, we use an enlarged dataset (with both successful and unsuccessful start-ups) to test Hypothesis 4, though the dataset is poor in quality because of the information restriction of ThomsonOne. Therefore, we test our main theoretical predictions (Hypotheses 1 to 3 ) based only on the successful start-ups.

24. We run all the regressions using start-up level data in the paper to match with the theoretical analyses in the previous sections. It is a cross-sectional dataset instead of panel data because each start-up has one IPO date or acquisition date. 
the definition from ThomsonOne, we have 549 CVC firms in our merged sample. As CVCs are subsidiaries invested by non-financial corporations, we manually identify the parent corporations of CVC firms and the industry classification (SIC code) of those parent corporations based on different information sources (such as Google, LexisNexis, etc). We redefine a VC firm as CVC if the firm has only one parent corporation and its industry classification is not a financial institution. We exclude those CVCs for which we cannot identify their parent corporations or those CVCs with parent corporations classified as financial institutions. With the new CVC definition, we have 437 CVC firms in the final sample. We use two measures to identify the characteristics of start-ups. ${ }^{25}$ The first measure is the dummy variable $C V C$ that takes a value of 1 if a start-up has at least one CVC investor and 0 if it is fully financed by IVCs. The second measure is the continuous variable CVC_Per calculated as the percentage of the investment amounts from CVC funds scaled by the start-up's total investment amount. This measure proxies for the degree of participation by CVC funds in a start-up.

To test whether CVC funds have different investment amounts, duration periods, and exit strategies compared with IVC funds, we construct three dependent variables at the start-up level: the total investment amount, the duration before the exit, and the exit route (IPO or acquisition). To measure the amount invested in a start-up (Investment Amount), we add up the disclosed investment amounts across all rounds. ${ }^{26}$ We define the duration before the exit (Duration) as the difference in days between the start-up's exit date (IPO date or acquisition date) and the date on which it received its first investment from VC investors. ${ }^{27}$ Finally, a start-up's exit strategy is denoted by the indicator variable $I P O$, which equals 1 if a start-up exits through an IPO and 0 if it exits through an acquisition.

Based on the prior literature, we control for a set of variables that may explain the investment, duration, and exit strategies. Masulis and Nahata (2009) argue that if a start-up and the parent company of the CVC investor are in the same industry, the latter is likely to have more information about the potential value of the venture than it would if the two firms operated in different industries. This argument leads to the endogeneity concern that CVC funds invest more because they have more precise information about the start-ups. To control for such effects, we include an indicator variable, CVC Strategic $R e .$, which is 1 if the parent company and the start-up have the same four-digit SIC code (i.e., they are competitors in the same industry), and 0 otherwise. ${ }^{28}$ Moreover, to mitigate the endogeneity concern that CVC firms are good at selecting better start-ups than IVC firms, or that they invest in more R\&D intensive projects, we include the control variable Patents in Stock, which measures the number of patents applied by a start-up before receiving any $\mathrm{VC}$ investments, as a proxy of the quality/innovativeness of the start-up. ${ }^{29}$

We also control for both syndicate size (i.e., the number of VC firms in one syndicated deal) and syndicate leader type. A syndicated deal involves two or more VC

25. See Chemmanur et al. (2013) for reference.

26. The ThomsonOne database displays both the disclosed and the estimated investment amounts for start-ups. To calculate the total investment amount for a certain start-up, we use the disclosed amount.

27. We also run some regressions with the variable Duration (Years) instead of Duration(Days).

28. We also define the indicator variable CVC Strategic Re. using a two-digit SIC code. The regression results are similar to those defined with a four-digit SIC code. These empirical results are available upon request.

29. As a robustness check, we use the total number of citations (adjusted for truncation problem) received by a start-up before the first investment round instead of the number of patents. Our results remain similar and are available upon request. 
firms that take equity stakes in an investment for a future joint payoff (see, for example, Toldra, 2010). A larger value of the variable Syndicate Size indicates that there are more investors in the start-up, which may influence the investment amount or the time before exit. The syndicate leader is the main fund in the syndicated deal. This fund organizes the syndicate and arranges and manages the project. The variable Syndicate Leader CVC takes the value 1 if the fund that provides the maximum investment amount in a syndication is a CVC firm and 0 otherwise (Masulis and Nahata, 2009). If a CVC fund is the leader, it has more decision power. Furthermore, more mature VC funds have more experience, a better reputation, and richer resources, which are likely to lead to higher investment levels in start-ups. Thus, in the regressions we also add the age of the VC fund as a proxy for the VC experience. The variable VC Fund Age is measured as the average fund age across all funds investing in the start-up.

To control for the influence of the stage of start-up development when the first investment happens on the investment amount and duration, we include an indicator variable, Early Invest Stage, which is 1 if the first investment is made at the seed or an early stage of the start-up's development. We also take into account the internal situation of the start-up at the time of exit. For instance, Aghion and Bolton (1992) and Cumming (2008) note that the balance of controlling power between the entrepreneur of a start-up and the VC investors may influence the exit strategy. Entrepreneurs are likely to prefer IPOs over acquisitions because the entrepreneurs can continue to enjoy the private benefits of running the firm in the event of an IPO, whereas venture capitalists may prefer acquisitions over IPOs because of the significant costs involved in preparing IPOs. Thus, the likelihood of IPOs increases as the controlling power of entrepreneurs increases. To account for this effect, we include the indicator variable Later Exit Stage in the regression. This variable is equal to 1 if the start-ups exit at the expansion or later stages and 0 if they exit at the seed or early stages. The intuition behind this variable is that entrepreneurs tend to have more control over their technologies and/or business operations if their start-ups exit in the expansion or later stages of the business cycle (Smith, 2005; Schwienbacher, 2010). Furthermore, we control for the stock market performance three months prior to the start-ups' exit dates (3-month MSCI). Presumably, a strong stock market performance can increase the value of IPO exits. Another concern is that the 2002 Sarbanes-Oxley Act raised the cost of going to an IPO, which may influence start-ups' choice of exit strategies. In our data sample, the percentage of IPO exits to acquisition changes a lot after the year 2002. For all the start-ups with IPO or acquisition exits, $51 \%$ of the start-ups have an IPO exit prior to 2002 whereas only $11 \%$ of them exit with an IPO after 2002. To take into account this effect and other possible macro-market influences, we control for the year fixed effect in all regression models.

According to our sample, there are around 60 industries based on 2-digit SIC codes, among which 14 industries have more than 20 start-ups in each industry. The major industries are the Business Service, Chemicals and Allied Products, Industrial Machinery and Equipment, Electronic Equipment, Communications, and Engineering Services, where venture capital investments are more common. ${ }^{30}$ About half of the startups in the sample are from the Business Service industry $(S I C=73)$. To control for the possibility that our results are mainly driven by this particular industry, we include an indicator variable, Industry 73 , in the analysis. Industry 73 takes the value of 1 if a start-up

30. We do not exclude the start-ups classified as financial institutions (i.e., SIC code between 6000 and 6999 ) in the following empirical analysis, but we check the robustness of our results by excluding the financial institutions, the results remain the same. The results without financial institutions are available upon request. 
TABLE I.

SUMMARY STATISTICS

\begin{tabular}{|c|c|c|c|c|c|}
\hline & No. of Obs. & Mean & Std. Dev. & Min & Max \\
\hline$\overline{\mathrm{CVC}}$ & 4,311 & 0.30 & 0.46 & 0 & 1 \\
\hline CVC_Per & 4,311 & 0.17 & 0.31 & 0 & 1 \\
\hline IPO & 4,311 & 0.34 & 0.47 & 0 & 1 \\
\hline Investment Amount & 4,311 & 33.60 & 81.74 & 0.02 & $4,653.06$ \\
\hline Duration (Days) & 4,311 & $1,729.28$ & $1,100.72$ & 50 & 8,310 \\
\hline Duration (Years) & 4,311 & 4.74 & 3.02 & 0.14 & 22.77 \\
\hline Investment Rounds & 4,311 & 4.37 & 2.88 & 1 & 27 \\
\hline Syndicate Size & 4,311 & 5.94 & 4.36 & 1 & 35 \\
\hline Syndicate Leader CVC & 4,311 & 0.03 & 0.16 & 0 & 1 \\
\hline VC Fund Size & 4,311 & 216.40 & 384.56 & 0.09 & $6,011.62$ \\
\hline VC Fund Age (Years) & 4,281 & 7.95 & 5.14 & 0 & 24.33 \\
\hline IVC Fund Age (Years) & 4,311 & 7.16 & 5.98 & 0 & 29 \\
\hline CVC Strategic Re. & 4,311 & 0.04 & 0.20 & 0 & 1 \\
\hline Industry MB & 4,311 & 13.73 & 21.87 & 0.78 & 432.1 \\
\hline 3-Month MSCI & 4,311 & $2,925.32$ & $1,304.45$ & 183.71 & $4,881.96$ \\
\hline Later Exit Stage & 4,311 & 0.82 & 0.38 & 0 & 1 \\
\hline Early Invest Stage & 4,311 & 0.72 & 0.45 & 0 & 1 \\
\hline Industry 73 & 4,311 & 0.47 & 0.50 & 0 & 1 \\
\hline Patent in Stock & 4,311 & 0.50 & 2.52 & 0 & 56 \\
\hline
\end{tabular}

This table reports the descriptive statistics for the sample of CVC- or IVC-backed start-ups with either IPO or acquisition exits from 1980 to 2004. The main data sources are the ThomsonOne private equity database, the NBER Patent Citation database, Compustat, and Morgan Stanley Capital International (MSCI). In our sample, around 30\% of the start-ups are partially financed by CVC funds, whereas the rest are financed exclusively by IVC funds. Moreover, $34 \%$ of the start-ups exit through IPOs and $66 \%$ exit through acquisitions

belongs to the Business Service industry and 0 otherwise. We also include the industry market to book value, denoted by Industry $M B$, to control for the effect of industry-level growth opportunities on the investment amount and duration strategy.

Appendix B provides the definition of all the variables used in the regressions. Table I presents the summary statistics of the variables. In our sample, around $30 \%$ of the start-ups are partially financed by CVC funds, whereas the rest are financed exclusively by IVC funds. Moreover, $34 \%$ of the start-ups exit through IPOs, and $66 \%$ exit through acquisitions.

The Pearson pairwise correlation between the indicator variable CVC and Investment Amount is 0.14 and between CVC and Duration is around 0.12. The correlation between Duration and Investment Amount is only 0.07. These correlations mitigate the concern that the main variables are highly correlated and may cause potential multicolinearity problems in the multivariate analysis of exit strategies. ${ }^{31}$

\section{EMPIRICAL RESULTS}

\subsection{UNIVARIATE EVIDENCE}

We start our analysis by providing some univariate evidence on the differences in the investment and duration strategies of CVC- and IVC-backed start-ups. Table II presents a univariate comparison of these two groups of start-ups. There are significant differences between them across several dimensions. For instance, CVC-backed startups have higher investment levels than IVC-backed start-ups. The average amount 
TABLE II.

COMPARISON BETWEEN CVC AND IVC FUNDS

\begin{tabular}{lrrrr}
\hline & \multicolumn{1}{c}{ IVC } & CVC & Difference & t-Statistics \\
\hline IPO & 0.33 & 0.35 & -0.014 & -0.86 \\
Investment Amount & 25.95 & 51.84 & -25.88 & $-12.29^{* * *}$ \\
Duration & $1,642.02$ & $1,937.76$ & -295.74 & $-7.99^{* * *}$ \\
Investment Rounds & 3.98 & 5.29 & -1.30 & $-13.89^{* * *}$ \\
Syndicate Size & 4.65 & 9.02 & -4.37 & $-29.78^{* * *}$ \\
VC Fund Size & 219.50 & 208.99 & 10.51 & 0.99 \\
VC Fund Age & 7.85 & 8.19 & -0.34 & $-2.17^{* *}$ \\
IVC Fund Age & 6.84 & 7.91 & -1.07 & $-5.57^{* * *}$ \\
Later Exit Stage & 0.79 & 0.89 & -0.10 & $-9.02^{* * *}$ \\
Early Invest Stage & 0.68 & 0.82 & -0.14 & $-10.48^{* * *}$ \\
Industry 73 & 0.44 & 0.53 & -0.09 & $-5.19^{* * *}$ \\
Patent in Stock & 0.44 & 0.63 & -0.19 & $-2.06^{* *}$ \\
\hline
\end{tabular}

This table reports the univariate analysis of the characteristics of CVC- and IVC-backed start-ups. CVC-backed start-ups have higher investment levels than IVC-backed start-ups. There is also a large gap between the average duration periods of these two types of start-ups. CVC-backed start-ups have more investment rounds, larger syndicate size, start investment at earlier stages, tend to exit at later stages of the business cycle, and own more patent applications before the first investment round. ${ }^{* * *},{ }^{* *}$ and ${ }^{*}$ denote statistical significance at $1 \%, 5 \%$, and $10 \%$ level. Please see Appendix B for variable definitions

invested in CVC-backed start-ups is approximately US\$52 million, whereas the average amount invested in IVC-backed start-ups is approximately US\$26 million. Consistent with Gompers and Lerner (2000), the difference in investment amounts between these two groups is approximately US\$26 million and is statistically significant at the $1 \%$ level. Furthermore, there is a large gap between the average duration periods of these two types of start-ups. The average duration for CVC-backed start-ups is 1,938 days, whereas the average duration for IVC-backed start-ups is 1,642 days. This difference is statistically significant. However, the difference in the IPO exit rates is not significant.

Concerning other variables, in contrast with IVC-backed start-ups, CVC-backed start-ups have more investment rounds and larger syndicate size, start investment at earlier stages and tend to exit at later stages of the business cycle. CVC-backed start-ups also own more patent applications before they receive the first investment from VC funds. This implies that there exists an identification problem, that is, CVCs invest in start-ups with better innovation quality compared with IVCs. We mitigate this problem by controlling for the total number of applied patents before the first investment year in all the regressions, as well as using the instrumental variable estimation and treatmenteffects regression model.

\subsection{FUND CHARACTERISTICS AND INVESTMENT STRATEGY}

We now examine the impact of CVC funds on the investment strategy of start-ups in a multivariate framework (Hypothesis 1). First, we use the following ordinary least squares model to estimate this effect:

$\ln$ Investment Amount $_{i}=\alpha_{0}+\alpha_{1} C V C_{i}+\sum_{k=1}^{10} \alpha_{k} Z_{k i}+\epsilon_{i}$.

In the above model, the variable Investment Amount denotes the total investment amount at the start-up level. The indicator variable $C V C$ captures whether a start-up receives $\mathrm{CVC}$ financing. 
Second, we address the problem that start-ups are not randomly matched with VC investors. Whether a start-up is CVC-backed or not is determined by observable or unobservable fund and start-up characteristics. In turn, such characteristics can lead to start-ups' choice for investment, as well as for duration and exit strategies, which are not completely explained by the fund characteristics. For instance, Gans et al. (2002) and Gans and Stern (2003) indicate that a higher relative cost of acquiring complementary assets reduces the possibility of IPO exits for start-ups. Because CVC-backed start-ups may have better access to complementary assets compared with those only backed by IVC funds, there can be more IPO exits related to CVC financing than IVC financing. We mitigate this endogeneity problem to some extent by controlling for the quality of start-ups prior to their receiving investment from VC funds. We use the total number of patent applications before the first investment round as a measure of quality. However, it is just a proxy of the start-ups' quality and the concern for endogeneity is not completely eliminated.

To further mitigate the identification problem, we use the treatment-effects regression model. It is a generalized version of the traditional two-step Heckman selection model (Heckman, 1979), which accounts for the effect of unobservables, that is, omitted variables that simultaneously affect the investor type and the investment, duration, and exit strategies (Maddala, 1983; Li and Prabhala, 2007; Bayar and Chemmanur, 2012). In the first stage regression, we seek to find out what influences the match between start-ups and CVC/IVC funds. The dependent variable of the first stage is the dummy variable $C V C$. The explanatory variables should capture the start-up characteristics and general market conditions that influence CVC/IVC investments in start-ups. The first variable that we include measures corporate liquidity. We claim that the probability of CVC financing is affected by the corporations' liquidity and extra cash (Da Gbadji et al., 2011). The intuition is that CVC funds are more willing to invest in start-ups in a year and industry where there is plenty of liquidity or extra cash. We measure the accounting liquidity in an industry in a given year using working capital (Harrison et al., 2011). We construct the variable 5-Year Avg WC, which captures the five-year average working capital in an industry right before CVCs invest in start-ups. With the same logic, we also construct the variable 5-Year Avg Net CF (five-year average net cash flow) in a year and industry to measure the extra cash. In addition, a start-up is more likely to receive CVC financing if that start-up is looking for VC financing in a year and geographic area when there is plenty of CVC funding. We measure the geographic area by the U.S. Metropolitan Statistical Areas (MSA). The variable Avg MSA CVC Inv/Total Inv captures the aggregate CVC funding near the start-ups' operating location in a given year. The variable is constructed as the total investments made by CVC funds in the year and the geographic area that the start-up operates as a percentage of the total VC investments for that year in the same geographic area. We also control for the total number of patents applied by the start-up and the investment stage before it receives VC investments. Industry and year-fixed effects are also controlled for. ${ }^{32}$ The result of the first stage regression is reported in Table III.

We find that all the explanatory variables have statistically significant effects on the probability that the start-ups receive CVC investments. Higher industry-level liquidity and cash flow increase the probability of CVC investment. Moreover, start-ups are more likely to be associated with CVCs if there is a higher share of CVC investments in the

32. Please refer to Appendix B for the detailed definition of the explanatory variables for the first stage treatment-effects estimation. 
TABLE III.

DETERMINANTS OF CVC INVESTMENT IN START-UPS

\begin{tabular}{lc}
\hline & DV: CVC Dummy Variable \\
\hline 5-Year Avg WC & $0.004^{* * *}$ \\
& $(5.69)$ \\
5-Year Avg Net CF & $0.022^{* * *}$ \\
Avg MSA CVC Inv/Total Inv & $(4.81)$ \\
& $1.888^{* * *}$ \\
Patents in Stock & $(14.39)$ \\
& $0.046^{* * *}$ \\
Seed Stage & $(6.07)$ \\
& $-1.76^{* * *}$ \\
Early Stage & $(-16.01)$ \\
& $-1.40^{* * *}$ \\
Expansion Stage & $(14.47)$ \\
Year Fixed Effects & $-0.59^{* * *}$ \\
Industry Fixed Effects & $(-6.25)$ \\
$N$ & Yes \\
\end{tabular}

This table reports the results of the first stage treatment-effects regression. Probit regression is estimated to predict the probability of a start-up to receive CVC investment in any investment round vs. only IVC financing. The dependent variable is the dummy variable $C V C$ taking a value of 1 if a start-up has at least one CVC investor and 0 if it is fully financed by IVCs. All available information that can influence the probability for a start-up to receive CVC financing is included as independent variables. Please see Appendix B for variable definitions. The Z-values are reported in parentheses. ${ }^{* * *},{ }^{* *}$ and ${ }^{*}$ denote statistical significance at $1 \%, 5 \%$, and $10 \%$ level

same MSA. Finally, CVCs tend to invest more in start-ups with a higher number of patent applications. ${ }^{33}$

Panel A of Table IV presents the results of the regressions that estimate Hypothesis 1 using OLS regression and Panel B shows the results of the second stage estimation of the treatment-effects model, by controlling for the inverse Mills ratio, which captures the unobservable effect on the match between CVC/IVC and start-ups. For Panel A, there are three models depending on the different independent variables included. For Panel B, there are only two models because the first stage estimation does not allow an endogenous variable that is not a dummy.

In Model 1, the estimated coefficient of $C V C$ is positive and statistically significant at the $1 \%$ level. This finding is consistent with the theoretical prediction that CVC funds invest more in start-ups than IVC funds do. The economic magnitude is also significant. The amounts invested in start-ups financed by CVC funds are $18 \%$ greater than the amounts invested in those financed by IVC funds. Moreover, if the syndicate leader of a start-up is a CVC investor, the start-up experiences an additional $34 \%$ increase in its investment level. In Model 2, we redefine the VC fund age and calculate it as the average age of IVC funds. Managers of younger IVC funds are more eager to show success than managers of older IVC funds. Therefore, the effect of the age of the fund should be stronger for IVC funds than for CVC funds that may stay in business for

33. In the treatment-effects estimation, the number of observations is around 700 less than in the OLS regression. This is because we have missing observations for the variable 5-Year Avg Net CF before year 1987 in Compustat. To eliminate the concern that the results in the treatment-effects estimation can be driven by different sample size from the OLS regression, we run the same OLS regression for the smaller sample set and we obtain very similar results. We do the same to the duration and exit strategies. The OLS results are available upon request. 
TABLE IV.

INVESTMENT STRATEGY

\begin{tabular}{|c|c|c|c|c|c|}
\hline & \multicolumn{3}{|c|}{$\begin{array}{l}\text { Panel A } \\
\text { OLS }\end{array}$} & \multicolumn{2}{|c|}{$\begin{array}{c}\text { Panel B } \\
\text { Treatment-effects }\end{array}$} \\
\hline & Model 1 & Model 2 & Model 3 & Model 1 & Model 2 \\
\hline $\mathrm{CVC}$ & $\begin{array}{c}0.177^{* * * *} \\
(5.02)\end{array}$ & $\begin{array}{c}0.165^{* * *} \\
(4.72)\end{array}$ & & $\begin{array}{c}0.312^{* * * *} \\
(4.63)\end{array}$ & $\begin{array}{c}0.295^{* * *} \\
(4.40)\end{array}$ \\
\hline CVC_Per & & & $\begin{array}{l}0.190^{* * * *} \\
\quad(3.68)\end{array}$ & & \\
\hline Investment Rounds & $\begin{array}{c}0.106^{* * *} \\
(18.74)\end{array}$ & $\begin{array}{c}0.106^{* * *} \\
(18.92)\end{array}$ & $\begin{array}{c}0.108^{* * * *} \\
(18.89)\end{array}$ & $\begin{array}{c}0.111^{* * *} \\
(17.11)\end{array}$ & $\begin{array}{c}0.112^{* * *} \\
(17.38)\end{array}$ \\
\hline Syndicate Size & $\begin{array}{c}0.132^{* * *} \\
(31.96)\end{array}$ & $\begin{array}{l}0.132^{* * * *} \\
(32.24)\end{array}$ & $\begin{array}{c}0.135^{* * *} \\
(32.90)\end{array}$ & $\begin{array}{l}0.139^{* * *} \\
(28.37)\end{array}$ & $\begin{array}{l}0.139 * * * \\
(28.66)\end{array}$ \\
\hline Syndicate Leader CVC & $\begin{array}{c}0.343^{* * *} \\
(4.16)\end{array}$ & $\begin{array}{c}0.334^{* * * *} \\
(4.08)\end{array}$ & $\begin{array}{c}0.341^{* * * *} \\
(3.99)\end{array}$ & $\begin{array}{c}0.403^{* * * *} \\
(4.55)\end{array}$ & $\begin{array}{c}0.394^{* * *} \\
(4.49)\end{array}$ \\
\hline ln(VC Fund Size) & $\begin{array}{c}0.355^{* * *} \\
(31.05)\end{array}$ & $\begin{array}{c}0.357^{* * *} \\
(31.44)\end{array}$ & $\begin{array}{c}0.355^{* * * *} \\
(31.00)\end{array}$ & $\begin{array}{c}0.352^{* * *} \\
(29.44)\end{array}$ & $\begin{array}{c}0.353^{* * *} \\
(29.76)\end{array}$ \\
\hline VC Fund Age & $\begin{array}{c}0.014^{* * *} \\
(5.51)\end{array}$ & & $\begin{array}{l}0.014^{* * * *} \\
\quad(5.44)\end{array}$ & $\begin{array}{c}0.013^{* * *} \\
(5.22)\end{array}$ & \\
\hline IVC Fund Age & & $\begin{array}{c}0.016^{* * * *} \\
(7.10)\end{array}$ & & & $\begin{array}{c}0.015^{* * *} \\
(6.44)\end{array}$ \\
\hline CVC Strategic Re. & $\begin{array}{l}0.035 \\
(0.51)\end{array}$ & $\begin{array}{l}0.032 \\
(0.46)\end{array}$ & $\begin{array}{l}0.067 \\
(0.98)\end{array}$ & $\begin{array}{c}0.035 \\
(0.5)\end{array}$ & $\begin{array}{l}0.031 \\
(0.45)\end{array}$ \\
\hline $\ln ($ Industry MB) & $\begin{array}{l}0.032 \\
(1.63)\end{array}$ & $\begin{array}{l}0.034^{*} \\
(1.75)\end{array}$ & $\begin{array}{l}0.034^{*} \\
(1.78)\end{array}$ & $\begin{array}{l}0.037^{*} \\
(1.84)\end{array}$ & $\begin{array}{c}0.039^{* *} \\
(1.96)\end{array}$ \\
\hline Early Invest Stage & $\begin{array}{l}-0.014 \\
(-0.47)\end{array}$ & $\begin{array}{l}-0.018 \\
(-0.61)\end{array}$ & $\begin{array}{l}-0.017 \\
(-0.58)\end{array}$ & $\begin{array}{l}0.012 \\
(0.33)\end{array}$ & $\begin{array}{l}0.007 \\
(0.21)\end{array}$ \\
\hline Industry 73 & $\begin{array}{c}-0.202^{* * *} \\
(-6.38)\end{array}$ & $\begin{array}{c}-0.203^{* * *} \\
(-6.47)\end{array}$ & $\begin{array}{c}-0.202^{* * *} \\
(-6.36)\end{array}$ & $\begin{array}{c}-0.223^{* * *} \\
(-6.61)\end{array}$ & $\begin{array}{c}-0.224^{* * *} \\
(-6.68)\end{array}$ \\
\hline Patent in Stock & $\begin{array}{c}0.017^{* * *} \\
(3.22)\end{array}$ & $\begin{array}{c}0.016^{* * * *} \\
(3.17)\end{array}$ & $\begin{array}{c}0.017^{* * *} \\
(3.29)\end{array}$ & $\begin{array}{c}0.015^{* * * *} \\
(2.84)\end{array}$ & $\begin{array}{c}0.014^{* * *} \\
(2.75)\end{array}$ \\
\hline Inverse Mills Ratio & & & & $\begin{array}{c}-0.119^{* * *} \\
(-2.69)\end{array}$ & $\begin{array}{c}-0.119^{* * *} \\
(-2.69)\end{array}$ \\
\hline Year Fixed Effects & Yes & Yes & Yes & Yes & Yes \\
\hline$N$ & 4,281 & 4,311 & 4,281 & 3,572 & 3,598 \\
\hline Adj. $R^{2}$ & 0.64 & 0.64 & 0.64 & $\mathrm{~N} / \mathrm{A}$ & $\mathrm{N} / \mathrm{A}$ \\
\hline
\end{tabular}

This table reports the results of the regressions that estimate whether CVC-backed start-ups receive more investment amount compared with those fully financed by IVCs. Panel A presents the results of OLS regressions and Panel B presents the results of the second stage treatment-effects regressions, by controlling for the inverse Mills ratios. The dependent variable for all the regressions is In(Investment Amount). It is the total investment amount received by a start-up before its IPO or acquisition exit. The main independent variable in Models 1 and 2 is the dummy variable $C V C$, which takes a value of 1 if a start-up has at least one CVC investor and 0 if it is fully financed by IVCs. In Model 3, whether a start-up receives CVC financing is measured by a continuous variable $C V C$ Per, which is the percentage of the investment amounts from CVC funds scaled by the start-up's total investment amount. Different from Models 1 and 3, Model 2 measures VC funds experience based on average IVC fund age, rather than the average fund age across all funds investing in the start-up. Please see Appendix B for other variable definitions. The $t$-statistics (for Panel A) and the Z-values (for Panel B) are reported in parentheses. ${ }^{* * *}$, ${ }^{* *}$ and ${ }^{*}$ denote statistical significance at $1 \%, 5 \%$, and $10 \%$ level

strategic reasons other than success. The results are robust to this alternative definition of fund age. Furthermore, in Model 3, we use the percentage of CVC investments as an alternative measure to capture the influence of CVC financing. The results are similar to those of Models 1 and $2 .{ }^{34}$ We find that more investment rounds, larger fund sizes, larger syndicate sizes, industries with more growth opportunities, higher number of patent applications before the first investment (i.e., more innovativeness), and being in

34. The number of observations in each regression is slightly different because we have missing information for the ages of some CVC funds. 
an industry different from the Business Service industry lead to increased investments in start-ups. We do not find any significant effect of the CVC funds' relationships with the start-ups (competitive or not) on the amounts invested in the start-up. ${ }^{35}$

Panel B shows the results of the second stage treatment-effects estimations, which are qualitatively similar to previously discussed OLS results. The inverse Mills ratios are statistically significant at the $1 \%$ level, which implies that there exists selection bias in the estimation of investment strategies. After controlling for the inverse Mills ratios, we still find that $C V C$ has a positive and very significant effect on the total investment amount. Taken together, the results of Panels A and B in Table IV strongly support the prediction that CVC-backed start-ups are associated with higher investment levels.

\subsection{FUND CHARACTERISTICS AND DURATION STRATEGY}

Our theoretical model predicts that the start-ups financed by CVC funds stay longer than those financed by IVC funds (Hypothesis 2). To test this prediction, we use a duration model because the dependent variable represents the period of time before the exit. We assume a Weibull distribution of the residual values and parametrically estimate the duration model. ${ }^{36}$ The hazard rate $h(t)$ and the survivor function $S(t)$ for the Weibull distribution are described as follows:

$$
h(t)=p t^{p-1} \exp (\alpha x) \quad S(t)=\exp \left(-\exp (\alpha x) t^{p}\right)
$$

In equation (7), $t$ stands for the number of days between the first investment date (initial time point) and the exit date, which is the duration in our sample. In addition, $\exp$ is the exponential transformation and $p$ is the shape parameter. The explanatory variables and their coefficients are denoted by vectors $x$ and $\alpha$. As before, the main independent variable of interest is $C V C$, which indicates whether the start-up has financing from CVC funds. We include the same set of control variables used in the regression that estimates the effect of CVC funds on the total investment amount. ${ }^{37}$ Similar to the investment strategy, we estimate the effect of fund characteristics on the start-ups' duration strategy using both the survival model and the survival model with a treatment-effects estimation. In the survival model, a Failure is defined as the start-up exiting on or before $t$. Our dataset is not censored. This means that all the start-ups exit (either through an IPO or acquisition) before the study is carried out. Thus, each start-up is considered to be a Failure case in the model. The only difference is how long it takes the start-ups to exit, which is captured by the duration variable $t$. A hazard rate greater than 1 for an explanatory variable indicates that there is a higher probability for start-ups to " $F a i l^{\prime \prime}$ which means that start-ups stay a shorter period before exit. An hazard rate smaller than 1 means a slower exiting process. In the treatment-effects estimation, we add the

35. Instead of using Industry 73 and Industry $M B$ to control for the industry effect, we run a similar regression controlling for the industry fixed effect on the investment strategy and find that the empirical results are very similar to the ones in Table IV. These empirical results are available upon request. We do not control for Industry $M B$, industry and year fixed effects at the same time because of multicollinearity concerns.

36. The assumption of a Weibull distribution is based on the Akaike Information Criterion (AIC) and the Bayesian Information Criterion (BIC). We also tried the semi-parametric estimation (COX estimation) of the survival model. However, the post-estimation PH-test rejected the proportional hazards assumption of the COX estimation.

37. To control for the industry effect on duration, we use the same strategy that we use for investment amount. We include either industry market-to-book value or industry fixed effect. The results remain similar. 
TABLE V.

DURATION STRATEGY

\begin{tabular}{|c|c|c|c|c|c|}
\hline & \multicolumn{3}{|c|}{$\begin{array}{l}\text { Panel A } \\
\text { Survival }\end{array}$} & \multicolumn{2}{|c|}{$\begin{array}{c}\text { Panel B } \\
\text { Treatment-effects }\end{array}$} \\
\hline & Model 1 & Model 2 & Model 3 & Model 1 & Model 2 \\
\hline $\mathrm{CVC}$ & $\begin{array}{c}0.988 \\
(-0.27)\end{array}$ & $\begin{array}{c}0.984 \\
(-0.37)\end{array}$ & & $\begin{array}{l}0.912^{*} \\
(-1.70)\end{array}$ & $\begin{array}{l}0.909^{*} \\
(-1.77)\end{array}$ \\
\hline CVC_Per & & & $\begin{array}{l}1.074 \\
(1.12)\end{array}$ & & \\
\hline Investment Rounds & $\begin{array}{l}0.865^{* * *} \\
(-19.01)\end{array}$ & $\begin{array}{l}0.864^{* * *} \\
(-19.25)\end{array}$ & $\begin{array}{l}0.866^{* * *} \\
(-18.81)\end{array}$ & $\begin{array}{l}0.852^{* * *} \\
(-17.91)\end{array}$ & $\begin{array}{l}0.850^{* * *} \\
(-18.28)\end{array}$ \\
\hline Syndicate Size & $\begin{array}{c}0.994 \\
(-1.27)\end{array}$ & $\begin{array}{c}0.994 \\
(-1.25)\end{array}$ & $\begin{array}{c}0.991^{*} \\
(-1.82)\end{array}$ & $\begin{array}{c}0.982^{* * *} \\
(-2.85)\end{array}$ & $\begin{array}{c}0.983^{* * *} \\
(-2.74)\end{array}$ \\
\hline Syndicate Leader CVC & $\begin{array}{l}1.122 \\
(1.17)\end{array}$ & $\begin{array}{l}1.094 \\
(0.91)\end{array}$ & $\begin{array}{l}1.064 \\
(0.61)\end{array}$ & $\begin{array}{l}1.145 \\
(1.22)\end{array}$ & $\begin{array}{l}1.109 \\
(0.94)\end{array}$ \\
\hline ln(VC Fund Size) & $\begin{array}{c}0.962^{* * *} \\
(-2.81)\end{array}$ & $\begin{array}{l}0.967^{* *} \\
(-2.49)\end{array}$ & $\begin{array}{c}0.963^{* * *} \\
(-2.78)\end{array}$ & $\begin{array}{c}0.975^{*} \\
(-1.75)\end{array}$ & $\begin{array}{c}0.980 \\
(-1.42)\end{array}$ \\
\hline VC Fund Age & $\begin{array}{c}1.00 \\
(0.01)\end{array}$ & & $\begin{array}{l}1.00 \\
(0.08)\end{array}$ & $\begin{array}{l}1.003 \\
(0.83)\end{array}$ & \\
\hline IVC Fund Age & & $\begin{array}{c}1.005^{* *} \\
(1.97)\end{array}$ & & & $\begin{array}{c}1.009^{* * *} \\
(3.18)\end{array}$ \\
\hline CVC Strategic Re. & $\begin{array}{c}0.984 \\
(-0.19)\end{array}$ & $\begin{array}{c}0.987 \\
(-0.16)\end{array}$ & $\begin{array}{c}0.961 \\
(-0.49)\end{array}$ & $\begin{array}{c}0.982 \\
(-0.22)\end{array}$ & $\begin{array}{c}0.981 \\
(-0.23)\end{array}$ \\
\hline ln(Industry MB) & $\begin{array}{c}0.846^{* * *} \\
(-7.65)\end{array}$ & $\begin{array}{c}0.849^{* * *} \\
(-7.5)\end{array}$ & $\begin{array}{c}0.845^{* * *} \\
(-7.69)\end{array}$ & $\begin{array}{c}0.862^{* * *} \\
(-6.18)\end{array}$ & $\begin{array}{c}0.867^{* * *} \\
(-6.01)\end{array}$ \\
\hline Early Invest Stage & $\begin{array}{l}1.008 \\
(0.24)\end{array}$ & $\begin{array}{l}1.008 \\
(0.22)\end{array}$ & $\begin{array}{l}1.007 \\
(0.19)\end{array}$ & $\begin{array}{c}1.158^{* * *} \\
(3.18)\end{array}$ & $\begin{array}{c}1.149^{* * *} \\
(3.03)\end{array}$ \\
\hline Industry 73 & $\begin{array}{c}1.167^{* * *} \\
(4.01)\end{array}$ & $\begin{array}{c}1.166^{* * *} \\
(4.01)\end{array}$ & $\begin{array}{c}1.164^{* * *} \\
(3.96)\end{array}$ & $\begin{array}{c}1.168^{* * *} \\
(3.61)\end{array}$ & $\begin{array}{c}1.169^{* * *} \\
(3.65)\end{array}$ \\
\hline Patent in Stock & $\begin{array}{c}0.999 \\
(-0.08)\end{array}$ & $\begin{array}{c}0.999 \\
(-0.09)\end{array}$ & $\begin{array}{c}0.999 \\
(-0.15)\end{array}$ & $\begin{array}{c}0.996 \\
(-0.58)\end{array}$ & $\begin{array}{c}0.996 \\
(-0.58)\end{array}$ \\
\hline Inverse Mills Ratio & & & & $\begin{array}{c}0.884^{* * *} \\
(-3.16)\end{array}$ & $\begin{array}{c}0.889^{* * *} \\
(-3.04)\end{array}$ \\
\hline Year Fixed Effects & Yes & Yes & Yes & Yes & Yes \\
\hline$N$ & 4,281 & 4,311 & 4,281 & 3,572 & 3,598 \\
\hline Log likelihood & $-4,039.4$ & $-4,069.7$ & $-4,038.8$ & $\mathrm{~N} / \mathrm{A}$ & $\mathrm{N} / \mathrm{A}$ \\
\hline
\end{tabular}

This table reports the results of the regressions that estimate whether CVC-backed start-ups stay longer than IVC-backed start-ups before a successful exit. Panel A presents the hazard rates of a survival model (parametrical estimation) based on a Weibull distribution of the residual values, and Panel B presents the hazard rates of the second stage treatment-effects regressions based on a survival model, by controlling for the inverse Mills ratios. In the survival estimation, a hazard rate greater than 1 indicates a higher probability for start-ups to exit earlier. A hazard rate smaller than 1 means a slower exiting process (i.e., staying longer before exiting via IPO or acquisition). The dependent variable for all the regressions is Duration for start-ups, defined as the number of days between the first investment date and the exiting date. The main independent variable in Models 1 and 2 is the dummy variable $C V C$, which takes a value of 1 if a start-up has at least one CVC investor and 0 if it is fully financed by IVCs. In Model 3, whether a start-up receives CVC financing is measured by a continuous variable CVC $\backslash$ Per, which is the percentage of the investment amounts from CVC funds scaled by the start-up's total investment amount. Different from Models 1 and 3, Model 2 measures VC funds experience based on average IVC fund age, rather than the average fund age across all funds investing in the start-up. Please see Appendix

$\mathrm{B}$ for other variable definitions. The Z-values are reported in parentheses. ***,** and ${ }^{*}$ denote statistical significance at $1 \%, 5 \%$, and $10 \%$ level

estimated inverse Mills ratio from the first stage as a controlling variable in the second stage estimation.

The hazard ratios of both estimations are shown in Table V. Panel A includes three regression models of normal survival estimation. The results of the treatment-effects estimation are presented in Panel B.

Similar to the results in Table IV, the inverse Mills ratios of the treatment-effects models implies an identification problem in the estimation of duration strategies. Although the effect of CVC on duration is not significant in the normal survival estimation, 
the results from the treatment-effects estimation after controlling for the inverse Mills ratio show that the CVC-backed start-ups stay significantly longer before exiting than the IVC-backed start-ups, which is consistent with Hypothesis 2. For both the survival estimation and the treatment-effects model, the start-ups with more investment rounds and a larger syndicate size stay much longer than those with less investment rounds and a smaller syndicate size. Moreover, start-ups that receive funds from larger VC funds and in industries with more growth opportunities stay longer prior to exit. However, the start-ups receiving funds from older IVC funds seem to stay for a shorter period of time. For both estimation methods, the impact of the competitive relationship between CVC funds and start-ups on duration is not significant. Together with the similar finding concerning the level of investment, this result suggests that whether CVC investors have more information about the start-ups and whether the CVC's parent company and the start-up are competitors do not appear to affect the investment and duration strategies. Finally, more innovative start-ups (i.e., those with more applied patents at the beginning of the investment round) do not stay significantly longer before exit than less innovative ones.

\subsection{FUND CHARACTERISTICS AND START-UP EXIT STRATEGIES}

In this section, we test the direct effect of CVC funds and their indirect impacts through investment and duration decisions on start-ups' exit strategies (Hypothesis 3 ) using the following model:

$$
\begin{aligned}
\text { Exit }_{i}= & \alpha_{0}+\alpha_{1} \text { CVC }_{i}+\alpha_{2} \ln \text { Duration }(\text { Days })_{i} \\
& +\alpha_{3} \ln \text { Investment Amount } \\
& +\sum_{k=1}^{9} \alpha_{k} Z_{k i}+\epsilon_{i} .
\end{aligned}
$$

The dependent variable Exit is an indicator variable that takes the value 1 if a start-up exits through an IPO and 0 if it exits through an acquisition. The main independent variables of interest are CVC, Investment Amount, and Duration (Days). We control for variables such as average fund size, number of total patent applications before the first investment, stock market condition, industry characteristics, year fixed effect, etc., as we discussed in Section 8.

To estimate the effect of VC fund characteristics on start-up exit strategies, we first use the logistic regression and OLS estimation. Then, to control for the identification concern related to $\mathrm{VC}$ investor type selection, we use both a treatment-effects estimation similar to the investment and duration strategies, and an instrumental variable estimation. The first stage treatment-effects estimation is the same as the results shown in Table III. In the second stage estimation, we include the inverse Mills ratio as a controlling variable.

For the instrumental variable approach, we construct two instruments which we also used as explanatory variables in the first stage estimation of the treatment-effects model. The first instrument is the variable Avg MSA CVC Inv/Total Inv. It measures the share of CVC investments over total investments in the geographical area of the start-up. The intuition is that the likelihood of CVC financing should increase with this share. We believe that the instrument reasonably satisfies the exclusion restriction because the share of CVC funding supply at MSA level can hardly influence the start-up level exit strategy. 
The second instrumental variable is the 5-Year Avg WC, which is constructed based on the intuition that CVC funds are more willing to invest in start-ups in a year and industry where there is plenty of liquidity. We believe that this variable influences the probability of start-ups receiving CVC investments and it should not affect the probability of a start-up's exit strategy in several years.

The results of the regressions that estimate Hypothesis 3 using the logistic estimation, treatment-effects estimation and instrumental variable estimation are presented in Tables VI, VII, and VIII, respectively. ${ }^{38}$ With logistic and OLS estimations, we present seven regression models depending on different definitions of some explanatory variables. For the treatment-effects estimation, we present models with the dummy variable $C V C$ as the independent variable because of the first stage estimation. In the instrumental variable estimation, we show models with the endogenous independent variable CVC or CVC_Per. These results are robust to the three above-mentioned econometric specifications and provide strong support for Hypotheses $3 a$ and $3 b .^{39}$

Table VI shows the regression results of logistic and OLS estimations. In Model 1, we investigate the effect of CVC financing on the exit strategy of start-ups without controlling for the duration effect and investment amount effect. We find that start-ups backed by CVC funds are more likely to have an IPO exit than those backed by IVC funds. This positive effect is statistically significant. On the contrary, in Model 2 , we control for the duration effect and investment amount effect but not for the investor type. The result shows that duration has a statistically significant and negative effect on the likelihood of IPO exit whereas investment amount has a statistically significant and positive effect. When we control for investor type, as well as duration and investment in Models 3, 5, 6, and 7, the effect of CVC funds on an IPO exit is not statistically significant when either the CVC indicator variable or the percentage of investment amounts made by CVC funds is used. These results, together with the results from Models 1 and 2, provide strong support for Hypothesis 3 and suggest that the type of investor does not directly impact the exit strategy over and above the effects of duration and investment amount. However, CVC funds indirectly influence the exit strategy through the investment amounts provided to the start-up and the duration of the start-up. Specifically, the coefficient of Ln(Investment Amount) is positive and statistically significant. In terms of economic magnitude, a $1 \%$ increase in the investment amount increases the probability of an IPO exit by $0.078 \%$, as evidenced in Model 7. Furthermore, a longer duration leads to a significantly lower probability of an IPO exit. A $1 \%$ increase in the duration decreases the probability of an IPO by $0.024 \%$.

In Model 4, we include a quadratic form of the duration to test the non-linear effect of duration on the exit strategy. The coefficient of this quadratic duration term is positive and statistically significant, which suggests that the negative effect of the

38. The number of observations in each regression is different because we have missing information for some CVC fund ages. In addition, observations with an exit year in 1981 and 1983 are dropped automatically in the logistic estimation for no IPO exits for the two years. For treatment-effects estimation, there are around 700 missing observations from the five-year average net cash flow before 1987.

39. In Tables VI-VIII, we include results estimating the same hypothesis with different econometric models (Logistic, OLS, treatment-effects and Instrumental Variable). The specifications are slightly different because of the different methodology characteristics. For instance, Model 2 is not included in Tables VII and VIII because both IV estimation and treatment-effects regression require a first stage regression depending on the investor type (CVC vs. IVC), which is omitted in Model 2's regression. Model 6 is not included in Table VII because the first stage estimation of treatment-effects regression does not allow an endogenous variable that is not a dummy. 


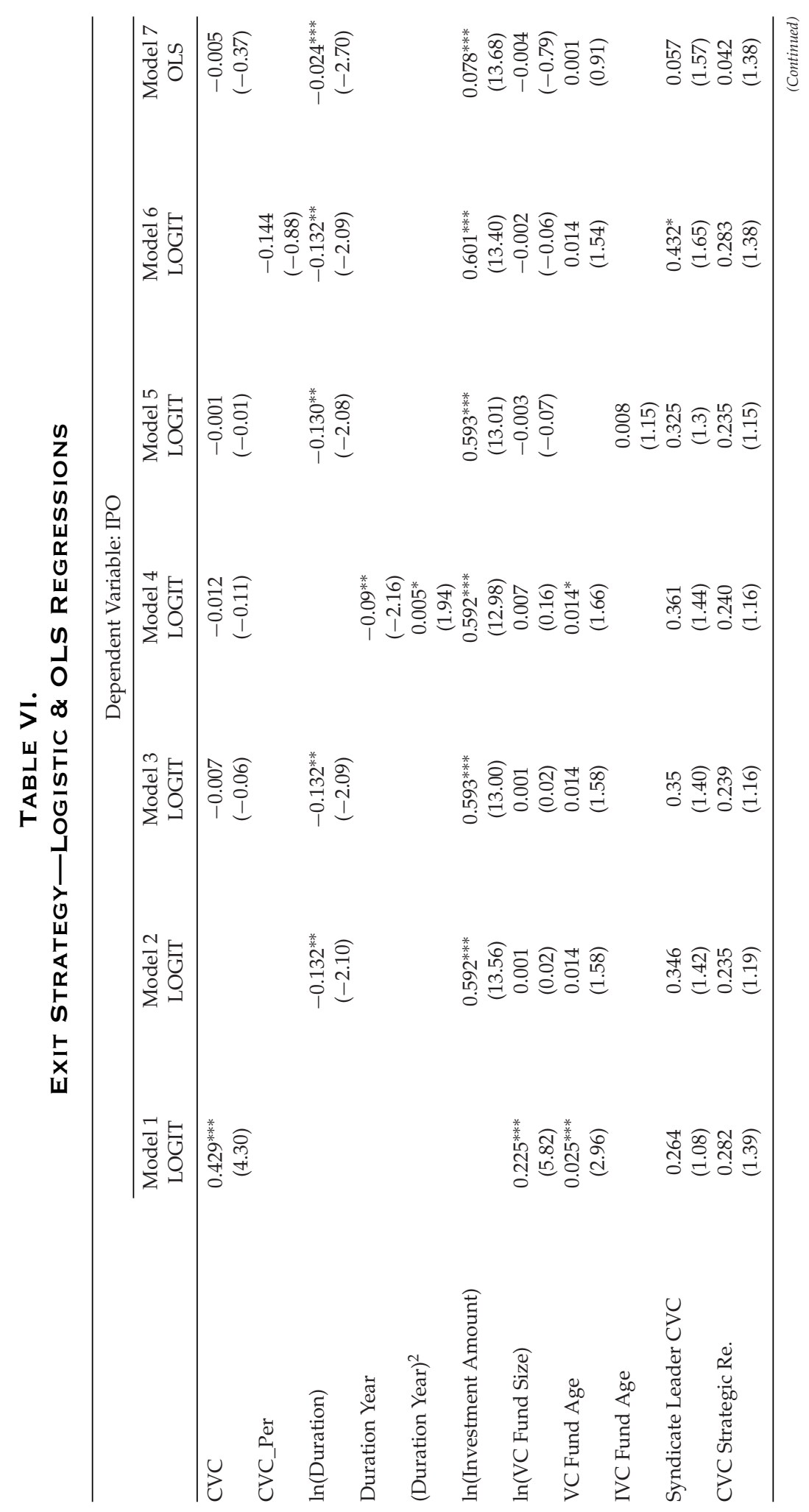




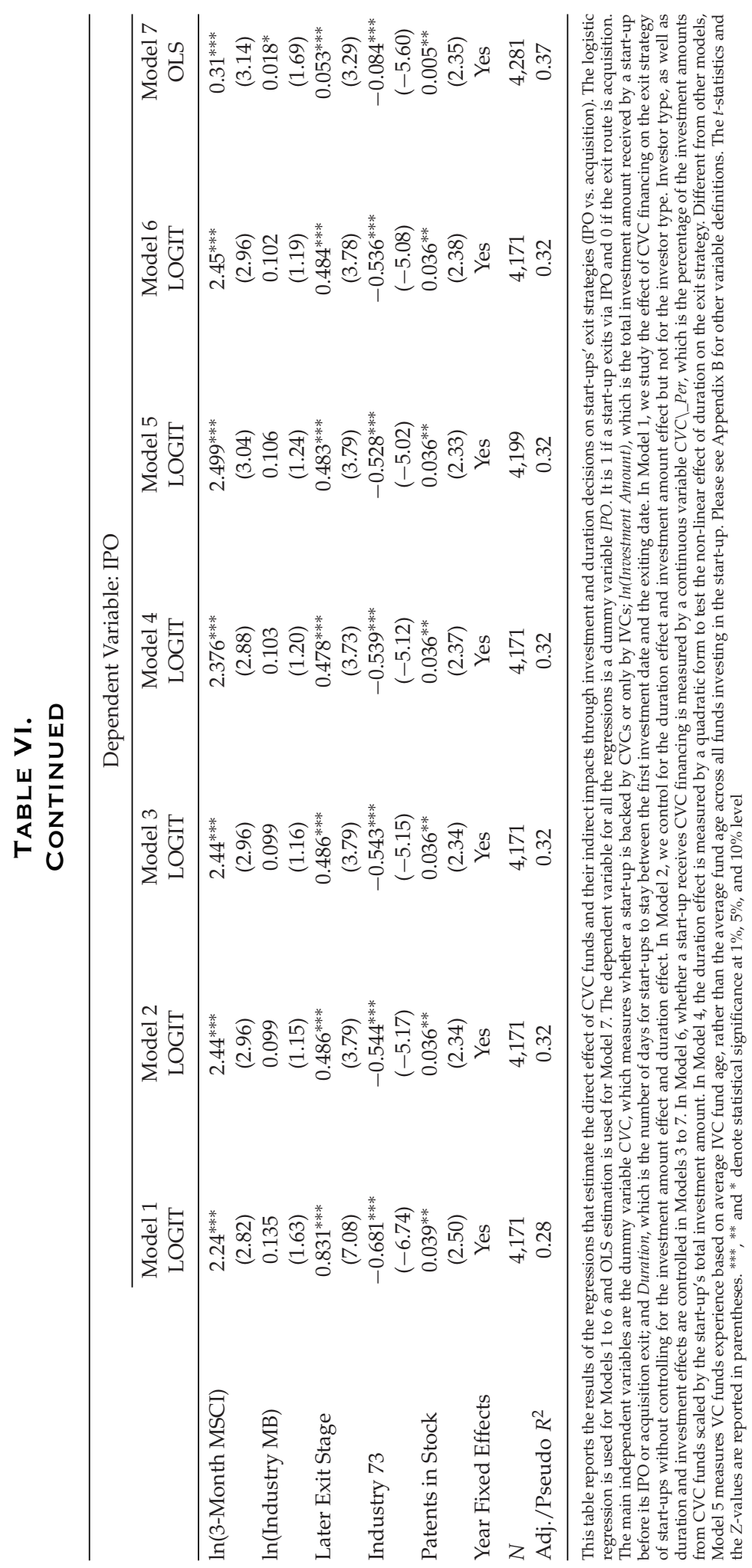


duration on the probability of an IPO exit is stronger if the duration is shorter. To better understand this quadratic effect, we run similar regressions for the start-ups with durations less than eight years and more than eight years, respectively. These subsample analyses confirm that the effect of duration on the likelihood of an IPO exit has two regions. The effect is linear and significant for the start-ups whose durations are less than eight years. Conversely, the effect is insignificant in a linear or quadratic manner if the duration for the start-up is more than eight years. In our dataset, the average duration of the start-ups is approximately four to five years, and more than $86 \%$ of the start-ups in our sample stay for less than eight years. Therefore, the quadratic effect of the duration does not alter our conclusions regarding the effect of duration on the exit strategy.

Furthermore, the results provide additional evidence of the effect of the discount rate on the exit strategy. Specifically, the effect of the VC fund size on the probability of an IPO is not statistically significant if both the duration and investment effects are controlled for in Models 2 to 7. However, in Model 1, when we remove the duration and investment amount, the estimated coefficient on Ln (VC Fund Size) is positive and statistically significant. The effect of the VC fund size is particularly interesting because the discount rate of a fund is likely to decrease with its size as larger funds have more resources than smaller funds. Thus, the fund size should have an effect on investment, duration, and exit strategies that is similar to the effect of the type of investor. According to Tables IV and V, the fund size also positively impacts the investment amount and the duration as the variable $C V C$, although Tables VI shows that fund size does not directly affect the exit strategy.

The sign of the control variables are also as expected. For instance, a stronger stock market performance three months before exit significantly increases the likelihood of IPOs. The estimated coefficient of the variable Later Exit Stage is positive and statistically significant. This finding is consistent with the results of the prior literature, which states that start-ups are more likely to exit through IPOs if entrepreneurs have controlling power (Cumming, 2008). Interestingly, start-ups with more patent applications at the beginning of the VC investment have a higher probability of exiting through an IPO than those with less applications. This confirms that higher quality start-ups exit more often through IPOs. Whether the start-ups and the parent companies of CVC funds are in the same industry has no significant impact on the exit strategy.

The second-stage regression results of treatment-effects model is included in Table VII. The coefficients of the inverse Mills ratios are not statistically significant in the estimation of the exit strategies. This confirms that the results in Table VI are quite plausible. The results after controlling for the inverse Mills ratio are qualitatively the same as those of the logistic estimation. If neither the investment nor duration effect is controlled for, CVC-financed start-ups have statistically more IPO exits than those only financed by IVCs. Once the investment and duration effects are controlled for, the VC fund type loses its influence on start-up exit strategies. Similar to the logistic regressions, Investment Amount and Duration have opposite effects on the probability of IPO exits. Both effects are statistically significant.

Table VIII shows both the first and second stage regression results using the IV approach for Models 3 to 6 of Table VI. The results from the first stage regressions suggest that the instruments significantly explain the $C V C$ variable. Both 5-Year Avg WC and Avg MSA CVC Inv/Total Inv are positively and significantly associated with the investor type (CVC vs. IVC) in all model specifications. The robust $F$-statistic is around 174 for Models 3 to 5 and 111 for Model 6. The robust F-statistics are well above the 
TABLE VII.

EXIT STRATEGY-TREATMENT-EFFECTS ESTIMATION

\begin{tabular}{|c|c|c|c|c|}
\hline & \multicolumn{3}{|c|}{ Dependent Variable: IPO } & \multirow[b]{2}{*}{ Model 5} \\
\hline & Model 1 & Model 3 & Model 4 & \\
\hline$\overline{\mathrm{CVC}}$ & $0.09^{* * *}$ & $\begin{array}{l}0.017 \\
0.67\end{array}$ & 0.015 & $\begin{array}{c}0.02 \\
(0.76)\end{array}$ \\
\hline $\ln$ (Duration) & & $\begin{array}{l}-0.035^{* * *} \\
(-3.32)\end{array}$ & $\begin{array}{l}-0.034^{* *} \\
(-3.24)\end{array}$ & \\
\hline Duration Year & & $-0.021^{* * *}$ & & $(-3.40)$ \\
\hline$\left(\right.$ Duration Year) ${ }^{2}$ & & & $0.002^{* * *}$ & \\
\hline $\ln ($ Investment Amount) & & $\begin{array}{c}0.098^{* * *} \\
(15.29)\end{array}$ & $\begin{array}{c}0.098^{* * *} \\
(15.31)\end{array}$ & $\begin{array}{l}0.098^{* * *} \\
(15.32)\end{array}$ \\
\hline $\ln ($ VC Fund Size) & $\begin{array}{l}0.034^{* * *} \\
(6.13)\end{array}$ & $\begin{array}{l}-0.006 \\
(-0.96)\end{array}$ & $\begin{array}{l}-0.005 \\
(-0.92)\end{array}$ & $\begin{array}{l}-0.006 \\
(-1.04)\end{array}$ \\
\hline VC Fund Age & $\begin{array}{l}0.003^{* *} \\
(2.55)\end{array}$ & $\begin{array}{l}0.001 \\
(0.5)\end{array}$ & $\begin{array}{c}0.001 \\
(0.56)\end{array}$ & $\begin{array}{l}0.014^{*} \\
(1.66)\end{array}$ \\
\hline IVC Fund Age & & & & $\begin{array}{l}0.0003 \\
(0.33)\end{array}$ \\
\hline Syndicate Leader CVC & $\begin{array}{c}0.06 \\
(1.47)\end{array}$ & $\begin{array}{c}0.062 \\
(1.57)\end{array}$ & $\begin{array}{c}0.063 \\
(1.58)\end{array}$ & $\begin{array}{c}0.06 \\
(1.53)\end{array}$ \\
\hline CVC Strategic Re. & $\begin{array}{c}0.042 \\
(1.30)\end{array}$ & $\begin{array}{c}0.03 \\
(0.97)\end{array}$ & $\begin{array}{c}0.03 \\
(0.98)\end{array}$ & $\begin{array}{c}0.03 \\
(0.99)\end{array}$ \\
\hline $\ln (3-$ Month MSCI) & $\begin{array}{l}0.034^{* * *} \\
(3.09)\end{array}$ & $\begin{array}{l}0.385^{* * *} \\
(3.60)\end{array}$ & $\begin{array}{l}0.381^{* * *} \\
(3.57)\end{array}$ & $\begin{array}{l}0.389^{* * *} \\
(3.64)\end{array}$ \\
\hline $\ln$ (Industry MB) & $\begin{array}{l}0.024^{* *} \\
(2.11)\end{array}$ & $\begin{array}{c}0.014 \\
(1.23)\end{array}$ & $\begin{array}{c}0.014 \\
(1.26)\end{array}$ & $\begin{array}{c}0.013 \\
(1.21)\end{array}$ \\
\hline Later Exit Stage & $\begin{array}{l}0.128^{* * *} \\
(7.33)\end{array}$ & $\begin{array}{l}0.053^{* * *} \\
(2.90)\end{array}$ & $\begin{array}{l}0.054^{* * *} \\
(2.99)\end{array}$ & $\begin{array}{l}0.053^{* * *} \\
(2.91)\end{array}$ \\
\hline Industry 73 & $\begin{array}{l}-0.106^{* * *} \\
(-6.4)\end{array}$ & $\begin{array}{l}-0.076^{* * *} \\
(-4.70)\end{array}$ & $\begin{array}{l}-0.076^{* * *} \\
(-4.70)\end{array}$ & $\begin{array}{l}-0.073^{* * *} \\
(-4.54)\end{array}$ \\
\hline Patents in Stock & $\begin{array}{l}0.006^{* *} \\
(2.46)\end{array}$ & $\begin{array}{l}0.005^{* *} \\
(2.07)\end{array}$ & $\begin{array}{l}0.005^{* *} \\
(2.09)\end{array}$ & $\begin{array}{l}0.005^{* *} \\
(2.04)\end{array}$ \\
\hline Inverse Mills Ratio & $\begin{array}{l}-0.026 \\
(-1.47)\end{array}$ & $\begin{array}{l}-0.025 \\
(-1.44)\end{array}$ & $\begin{array}{c}-0.023 \\
(-1.37)\end{array}$ & $\begin{array}{l}-0.025 \\
(-1.46)\end{array}$ \\
\hline Year Fixed Effects & Yes & Yes & Yes & Yes \\
\hline$N$ & 3,572 & 3,572 & 3,572 & 3,598 \\
\hline
\end{tabular}

This table reports the results of the second stage treatment-effects regressions that estimate the direct effect of CVC funds and their indirect impacts through investment and duration decisions on start-ups' exit strategies (IPO vs. acquisition), by controlling for the inverse Mills ratios. The dependent variable for all the regressions is a dummy variable IPO. It is 1 if a start-up exits via IPO and 0 if the exit route is acquisition. The main independent variables are the dummy variable $C V C$, which measures whether a start-up is backed by CVCs or only by IVCs; ln (Investment Amount), which is the total investment amount received by a start-up before its IPO or acquisition exit; and Duration, which is the number of days for start-ups to stay between the first investment date and the exiting date. In Model 1, we study the effect of CVC financing on the exit strategy of start-ups without controlling for the investment amount effect and duration effect. Investor type, as well as duration and investment effects are controlled in Models 3 to 5. In Model 4, the duration effect is measured by a quadratic form to test the non-linear effect of duration on the exit strategy. Different from other models, Model 5 measures VC funds experience based on average IVC fund age, rather than the average fund age across all funds investing in the start-up. Please see Appendix B for other variable definitions. The Z-values are reported in parentheses. ${ }^{* * *},{ }^{* *}$ and ${ }^{*}$ denote statistical significance at $1 \%, 5 \%$, and $10 \%$ level

critical value suggested by Stock et al. (2002) to be a strong instrument. ${ }^{40}$ Furthermore, the Hansen-Sargan J-statistics from the over-identifying test have $p$-values larger than 0.58. These results assure the appropriateness of the two instrumental variables.

40. Stock et al. (2002) develop the suggested critical F-statistics for different numbers of instruments. In the case of two instruments, the F-statistic should be at least 11.59 to ensure that the instruments are not weak. 


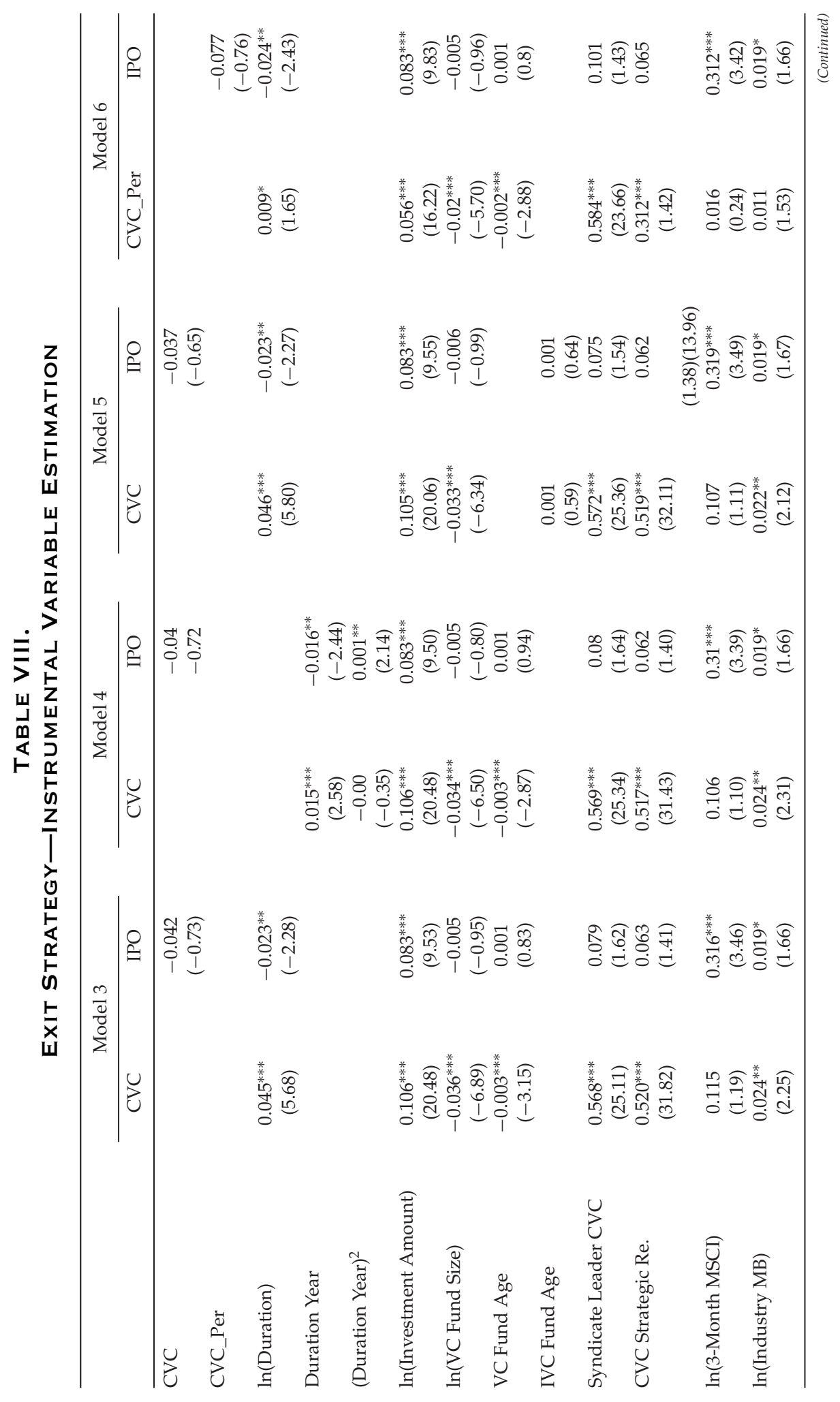




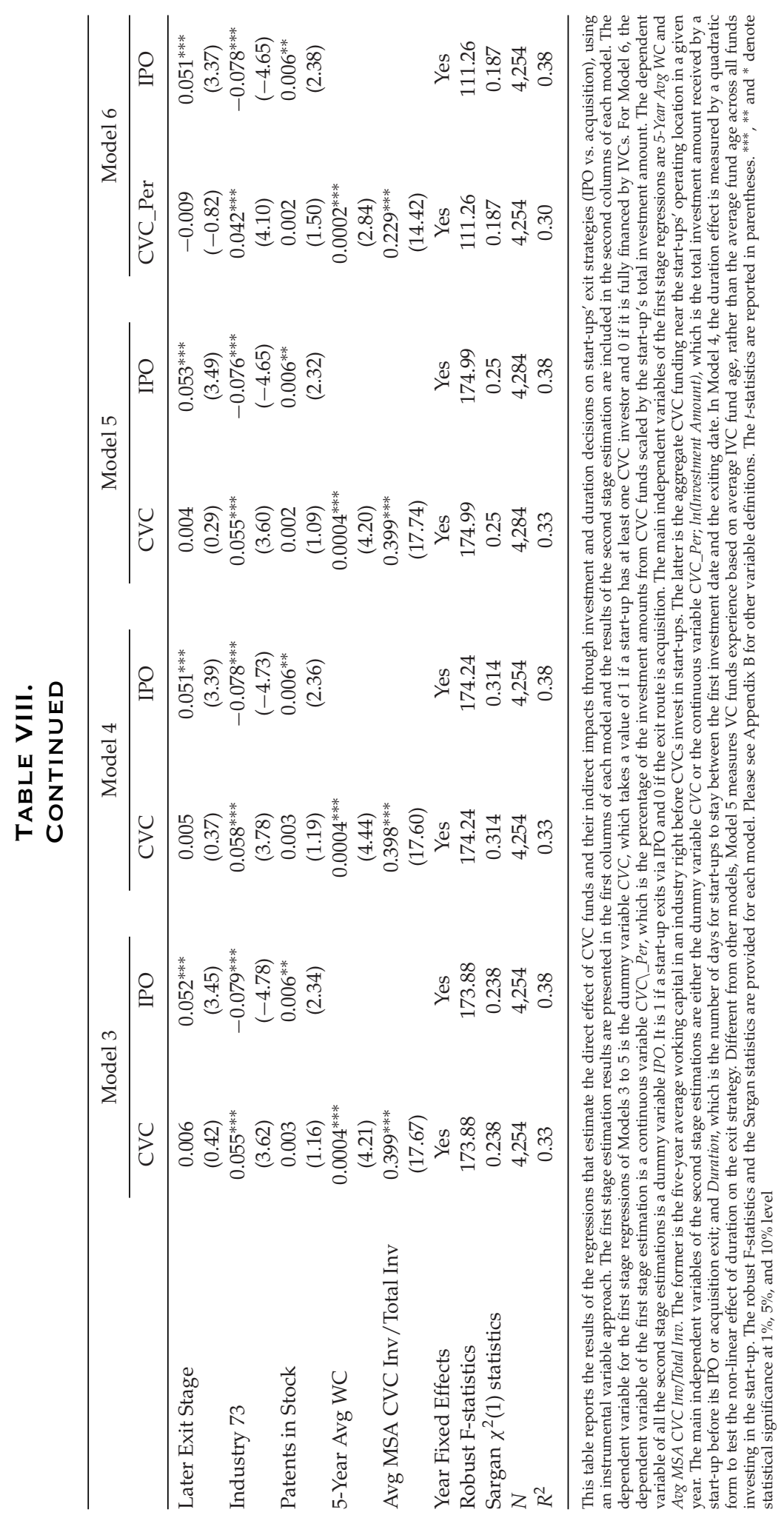


TABLE IX.

RATE OF SUCCESSFUL EXITS

\begin{tabular}{lcc}
\hline & & Dependent Variable: Failure \\
\cline { 2 - 3 } & Model 1 & Model 2 \\
& LOGIT & LOGIT \\
\hline CVC & -0.015 & 0.12 \\
CVC_per & $(-0.22)$ & $(0.89)$ \\
& & -0.021 \\
$\ln ($ Duration) & & $(-0.59)$ \\
& -0.023 & -0.011 \\
$\ln ($ Investment Amount) & $(-0.65)$ & $(-0.40)$ \\
& -0.005 & 0.045 \\
Syndicate Leader CVC & $(-0.17)$ & $(0.29)$ \\
& 0.078 & -0.009 \\
ln(VC Fund Size) & $(0.49)$ & $(0.35)$ \\
CVC Strategic Re. & -0.011 & 0.12 \\
& $(-0.41)$ & $(0.30)$ \\
Later Exit Stage & 0.18 & 0.064 \\
Industry 73 & $(0.44)$ & $(0.73)$ \\
Year Fixed Effects & 0.064 & -0.184 \\
Industry Fixed Effects & $(0.73)$ & $(-0.17)$ \\
$N$ & -0.175 & No \\
Pseudo $R^{2}$ & $(-0.16)$ & Yes \\
\hline
\end{tabular}

The table presents the results of the logistic regressions that estimate the effects of CVC investors on the successful exit rate. The dependent variable is Failure, which is 1 if a start-up has neither an IPO exit nor an acquisition exit and 0 if it exits through an IPO or an acquisition route. The main independent variables are the variables CVC, which measure whether a start-up is backed by CVCs or only by IVCs; In(Investment Amount) which is the total investment amount received by a start-up before its IPO or acquisition exit; and Duration which is the number of days for start-ups to stay between the first investment date and the exiting date. In Model 1, we measure CVC vs. IVC financing using the dummy variable CVC, which takes a value of 1 if a start-up has at least one CVC investor and 0 if it is fully financed by IVCs. In Model 2, whether a start-up receives CVC financing is measured by a continuous variable $C V C \backslash \_P e r$, which is the percentage of the investment amounts from CVC funds scaled by the start-up's total investment amount. Please see Appendix B for other variable definitions. The Z-values are reported in parentheses. ${ }^{* * *},{ }^{* *}$ and ${ }^{*}$ denote statistical significance at $1 \%, 5 \%$, and $10 \%$ level

\subsection{FUND CHARACTERISTICS AND RATE OF SUCCESSFUL EXITS}

Our theoretical model also predicts the indirect effects of the amounts invested by CVC funds on the rate of successful exits by start-ups (Hypothesis 4). To test these effects, we use a dataset that includes both the successful and unsuccessful start-ups in the United States with the first investment year from 1980 to 2004 . We construct a new dependent variable, Failure, which is equal to 1 if a start-up has neither an IPO exit nor an acquisition exit, as indicated by the ThomsonOne database and SDC Global New Issues Database, and 0 if it exits through an IPO or an acquisition route. If this is the case, the duration of the start-up is defined as the number of days between the first and last investment dates. We control for a set of explanatory variables similar to that in the IPO exit regression. ${ }^{41}$

Table IX presents the results of the logistic regressions of Hypothesis 4 . In Models 1 and 2, we use the CVC indicator variable and the percentage of the amount invested by the CVC funds to measure whether a start-up is backed by CVC funds. We

41. We exclude some control variables, such as the industry market-to-book value and fund age, because of data insufficiency. Furthermore, we do not observe the dates on which the start-ups are defined as a failure. Hence, we also remove the control variables that require exact defunction dates. 
find that funds' characteristics, duration, investment amount, and the identity of the syndicate leader (i.e., whether the CVC is the syndicate leader) do not have significant influence on the probability of failure. This discrepancy may be due to the abovementioned poor quality of the ThomsonOne dataset with regard to the set of failures because of information restrictions. Our theoretical predictions regarding the impact of CVC funds on the exit strategy are closer to those of Chemmanur and Loutskina (2008), who find that CVC investments in start-ups lead to a higher, albeit not significant, rate of successful exit. Furthermore, a higher investment level increases the rate of success, as predicted by our theoretical model. Other empirical studies also confirm that CVCbacked start-ups perform better than IVC-backed start-ups. For example, Dushnitsky and Shapira (2010) find that CVC-backed start-ups exhibit a higher rate of successful portfolio exits. Depending on the CVC portfolio manager's compensation incentives, the increase in the rate of successful exits ranges from $9.7 \%$ to $20 \%$.

\section{CONCLUSION}

In this paper, we study the optimal initial and exit decisions made by start-ups. In particular, we focus on the difference in behavior between CVC-backed start-ups and IVC-backed start-ups.

In our theoretical analysis, we find that CVC-backed start-ups have longer durations before their exits and larger investment levels than those financed by IVC funds. In turn, these properties lead to higher rates of successful exit and to two opposite impacts on the likelihood of an IPO exit. A longer duration, which implies the existence of more information in the acquisition market, increases the probability of the start-up searching for an acquirer. Conversely, higher investment levels, which increase the value of the start-up, encourage an IPO exit.

We find strong empirical support for our theoretical predictions by using data from the ThomsonOne, the SDC Global New Issues, and the NBER Patent databases. The presence of CVC financing leads the start-ups to higher levels of investment and to stay longer before exiting. Moreover, the effect of the venture capital funds' characteristics on the start-ups' exit strategies can be explained by the investment and duration decisions. Shorter durations and greater investment levels lead to a greater likelihood of IPO exits. With these effects taken into consideration, it can be seen that the exit decision is not significantly influenced by whether the venture capital fund is corporate or independent.

In our empirical analyses, we have taken into account the endogeneity concern that start-ups are not randomly assigned to CVC or IVC funds. We mitigate the endogeneity problem by controlling for the quality of the start-ups before receiving VC investment. Further, we use the treatment-effects model and instrumental variable estimation to account for potential unobservables. In particular, we propose a new instrument, the average working capital in an industry, which we believe can help in other empirical research questions. However, we acknowledge that it is difficult to completely solve the endogeneity problem in our model. Therefore, our results should be taken with caution.

\section{Appendix A: Theoretical ProOfs}

Proof of Proposition 2: The proof follows the discussions before Propositions 1 and 2. We notice that equation (2) gives a solution $p^{*}(V) \leq 1$ if $V \leq \frac{F}{\beta-\frac{m}{2}}$, in which case 
$p^{*}(V)=\frac{F}{\left(\beta-\frac{m}{2}\right) V}$. Therefore, in this region of $V$, the deal price for a startup with potential value $V$ is $m \frac{p^{*}(V)}{2} V=\frac{m F}{2\left(\beta-\frac{m}{2}\right)}$. If $V>\frac{F}{\beta-\frac{m}{2}}$, then $p^{*}(V)=1$ and the deal price is $\frac{1}{2} m V$.

Proof of Proposition 3.1: Given that $V$ is uniformly distributed over the interval $[f(I), \hat{V}+f(I)]$, we have that $1-F(0)=\frac{\hat{V}+f(I)}{\hat{V}}$. Therefore, the rate of IPO exits over the total successful exits is either

$$
\frac{\hat{V}}{(\hat{V}+f(I))} \int_{\frac{F}{\beta-m}}^{\hat{V}+f(I)}\left[1-\frac{F}{(\beta-m) V}\right] \frac{1}{\hat{V}} d V,
$$

or

$$
\frac{\hat{V}}{(\hat{V}+f(I))} \int_{\frac{F}{\beta-\frac{m}{2}}}^{\hat{V}+f(I)}\left[1-\frac{F}{\left(\beta-\frac{m}{2}\right) V}\right] \frac{1}{\hat{V}} d V,
$$

depending on the information about $p$. Moreover,

$$
\begin{aligned}
& \frac{\partial}{\partial I}\left(\frac{\hat{V}}{(\hat{V}+f(I))} \int_{\frac{F}{\beta-m}}^{\hat{V}+f(I)}\left(1-\frac{F}{(\beta-m) V}\right) \frac{1}{\hat{V}} d V\right) \\
& =\frac{f^{\prime}(I)}{(\hat{V}+f(I))^{2}}\left(\left(\hat{V}+f(I)-\frac{F}{(\beta-m)}\right)-\int_{\frac{F}{\beta-m}}^{\hat{V}+f(I)}\left(1-\frac{F}{(\beta-m) V}\right) d V\right) \\
& =\frac{f^{\prime}(I)}{(\hat{V}+f(I))^{2}}\left(\int_{\frac{F}{\beta-m}}^{\hat{V}+f(I)} \frac{F}{(\beta-m) V} d V\right)>0 .
\end{aligned}
$$

Therefore, the expression (A1) is increasing in I. A similar argument allows us to prove that (A2) is also increasing in $I$.

The proof of Proposition 3.2 is immediate.

Proof of Lemma 1: The expected utilities $E U_{0}(I)$ and $E U_{o o}(I)$ are computed as the integral over the set $A$ of all the possible values of $(V, p)$ that can exist given $I$. We divide this set into three subsets: We denote $A_{1}$ the subset composed of all values for which the start-up seeks an acquirer in both cases; we denote $A_{2}$ the subset of all values for which the start-up goes to an IPO in both cases; and we denote $A_{3}$ the subset of values of $(V, p)$ for which the start-up seeks an acquirer if the acquirer knows $p$ whereas it goes to an IPO if the acquirer does not know $p$.

First, the value of the start-up profit function is the same in $E U_{o}(I)$ and $E U_{o o}(I)$ in $(V, p) \in A_{2}$ because $U_{o}(V, p)=U_{o o}(V, p)$ in this region of parameters. Second, the integral of the expected value for all the parameters $(V, p)$ in $A_{1}$ must also be the same in $E U_{o}(I)$ and $E U_{o o}(I)$ because, for any $V$, if the acquirer does not know $p$, the deal price reflects the expected value given the set of $p$ s that go to the acquisition market, multiplied by the bargaining power $m$. Finally, in $A_{3}$, the value of the start-up in the expression $E U_{o}(I)$ is higher than in $E U_{o o}(I)$ for the reason we have provided in the main text: if the acquirer does not know $p$, the equlibrium deal price for the parameters in $A_{3}$ is lower than the expected value in the start-up goes to an IPO.

Therefore, $E U_{o}(I)$ is always higher than $E U_{o o}(I)$. Moreover, the inequality is strict as long as $A_{3}$ is non-empty, which always holds if IPOs can happen (as ensured by our assumptions). 
Proof of Proposition 5: The optimal values $d^{*}$ and $I^{*}$ are characterized by

$\frac{\partial U}{\partial d}\left(d^{*}, I^{*}\right)=0$,

$\frac{\partial U}{\partial I}\left(d^{*}, I^{*}\right)=0$.

We differentiate equations (A3) and (A4) and solve the system to obtain that, at $\left(d^{*}, I^{*}\right)$,

$\frac{\partial I^{*}}{\partial r}=-\frac{\Lambda_{I}}{\Delta}$

$\frac{\partial d^{*}}{\partial r}=-\frac{\Lambda_{d}}{\Delta}$

where

$\Lambda_{I}=\frac{\partial^{2} U}{\partial d^{2}} \frac{\partial^{2} U}{\partial I \partial r}-\frac{\partial^{2} U}{\partial I \partial d} \frac{\partial^{2} U}{\partial d \partial r}$

$\Lambda_{d}=\frac{\partial^{2} U}{\partial I^{2}} \frac{\partial^{2} U}{\partial d \partial r}-\frac{\partial^{2} U}{\partial I \partial d} \frac{\partial^{2} U}{\partial I \partial r}$

and

$\Delta=\frac{\partial^{2} U}{\partial I^{2}} \frac{\partial^{2} U}{\partial d^{2}}-\left(\frac{\partial^{2} U}{\partial I \partial d}\right)^{2}$.

Before the analysis of the second derivatives of the function $U(d, I)$, we analyze the functions $E U_{o}(I)$ and $E U_{o o}(I)$.

Taking into account that $d \Gamma(V ; I)=\frac{1}{V}$, and Propositions 1 and 2 , we have

$$
\begin{aligned}
E U_{0}(I)= & \int_{0}^{\frac{F}{\beta-m}} \int_{0}^{1} m p V d p \frac{1}{\widehat{V}} d V+\int_{\frac{F}{\beta-m}}^{\widehat{V}+f(I)} \int_{0}^{\frac{F}{(\beta-m) V}} m p V d p \frac{1}{\widehat{V}} d V \\
& +\int_{\frac{F}{\beta-m}}^{\widehat{V}+f(I)} \int_{\frac{F}{(\beta-m) V}}^{1}(\beta p V-F) d p \frac{1}{\widehat{V}} d V \\
= & \frac{1}{2 \widehat{V}} \int_{0}^{\frac{F}{\beta-m}} m V d V+\frac{1}{2 \widehat{V}} \int_{\frac{F}{\beta-m}}^{\widehat{V}+f(I)} m \frac{F^{2}}{(\beta-m)^{2} V} d V \\
& +\frac{1}{\widehat{V}} \int_{\frac{F}{\beta-m}}^{\widehat{V}+f(I)}\left(\frac{1}{2} \beta V-\frac{1}{2} \frac{\beta F^{2}}{(\beta-m)^{2} V}-F+\frac{F^{2}}{(\beta-m) V}\right) d V \\
& =\frac{1}{2 \widehat{V}} \int_{0}^{\frac{F}{\beta-m}} m V d V+\frac{1}{\widehat{V}} \int_{\frac{F}{\beta-m}}^{\widehat{V}+f(I)}\left(\frac{1}{2} \beta V+\frac{1}{2} \frac{F^{2}}{(\beta-m) V}-F\right) d V,
\end{aligned}
$$

and similarly,

$$
E U_{o o}(I)=\int_{0}^{\frac{F}{\beta-\frac{m}{2}}} \int_{0}^{1} \frac{1}{2} m V d p \frac{1}{\widehat{V}} d V+\int_{\frac{F}{\beta-\frac{m}{2}}}^{\widehat{V}+f(I)} \int_{0}^{\frac{F}{\left(\beta-\frac{m}{2}\right) V}} \frac{1}{2} m \frac{F}{\left(\beta-\frac{m}{2}\right)} d p \frac{1}{\widehat{V}} d V
$$




$$
\begin{aligned}
& +\int_{\frac{F}{\beta-\frac{m}{2}}}^{\widehat{V}+f(I)} \int_{\frac{F}{\left(\beta-\frac{m}{2}\right) V}}^{1}(\beta p V-F) d p \frac{1}{\widehat{V}} d V=\frac{1}{2 \widehat{V}} \int_{0}^{\frac{F}{\beta-\frac{m}{2}}} m V d V \\
& +\frac{1}{\widehat{V}} \int_{\frac{F}{\beta-\frac{m}{2}}}^{\widehat{V}+f(I)}\left(\frac{1}{2} \beta V-\frac{1}{2} \frac{(\beta-m) F^{2}}{\left(\beta-\frac{m}{2}\right)^{2} V}+\frac{F^{2}}{\left(\beta-\frac{m}{2}\right) V}-F\right) d V .
\end{aligned}
$$

From the expressions of $E U_{o}(I)$ and $E U_{o o}(I)$ we obtain

$$
\begin{aligned}
& E U_{o}^{\prime}(I)=\frac{f^{\prime}(I)}{\widehat{V}}\left(\frac{1}{2} \beta(\widehat{V}+f(I))+\frac{1}{2} \frac{F^{2}}{(\beta-m)(\widehat{V}+f(I))}-F\right), \\
& E U_{o o}^{\prime}(I)=\frac{f^{\prime}(I)}{\widehat{V}}\left(\frac{1}{2} \beta(\widehat{V}+f(I))-\frac{1}{2} \frac{(\beta-m) F^{2}}{\left(\beta-\frac{m}{2}\right)^{2}(\widehat{V}+f(I))}+\frac{F^{2}}{\left(\beta-\frac{m}{2}\right)(\widehat{V}+f(I))}-F\right) .
\end{aligned}
$$

As it is intuitive and easy to check, $E U_{o}^{\prime}(I)>0$ and $E U_{o o}^{\prime}(I)>0$.

We now analyze the sign of the second derivatives of the function $U(d, I)$.

$\frac{\partial^{2} U}{\partial d^{2}}\left(d^{*}, I^{*}\right)=e^{-r d}\left[h^{\prime \prime}(d)-r h^{\prime}(d)\right]\left[E U_{o}(I)-E U_{o o}(I)\right]$.

In equation (A11), $h^{\prime}(d)>0$ and $h^{\prime \prime}(d)<0$. Moreover, Lemma 1 implies that $E U_{o}(I)>$ $E U_{o o}(I)$. Therefore, $\frac{\partial^{2} U}{\partial d^{2}}\left(d^{*}, I^{*}\right)<0$.

$\frac{\partial^{2} U}{\partial I \partial r}\left(d^{*}, I^{*}\right)=-d<0$.

$\frac{\partial^{2} U}{\partial I^{2}}\left(d^{*}, I^{*}\right)=e^{-r d}\left[h(d) E U_{o}^{\prime \prime}(I)+(1-h(d)) E U_{o o}^{\prime \prime}(I)\right]<0$

because

$$
\begin{aligned}
E U_{o}^{\prime \prime}(I) & =\frac{f^{\prime \prime}(I)}{\widehat{V}}\left(\frac{1}{2} \beta(\widehat{V}+f(I))+\frac{1}{2} \frac{F^{2}}{(\beta-m)(\widehat{V}+f(I))}-F\right) \\
& +\frac{1}{2} \frac{f^{\prime}(I)^{2}}{\widehat{V}}\left(\beta-\frac{F^{2}}{(\beta-m)(\widehat{V}+f(I))^{2}}\right)<0 .
\end{aligned}
$$

Similarly, $E U_{o o}^{\prime \prime}(I)<0$ if $f(I)$ is concave enough.

$$
\frac{\partial^{2} U}{\partial d \partial r}\left(d^{*}, I^{*}\right)=-e^{-r d}\left[h(d) E U_{o}(I)+(1-h(d)) E U_{o o}(I)\right]<0 .
$$

Finally

$$
\frac{\partial^{2} U}{\partial I \partial d}\left(d^{*}, I^{*}\right)=-r+e^{-r d} h^{\prime}(d)\left[E U_{o}^{\prime}(I)-E U_{o o}^{\prime}(I)\right],
$$

with

$$
E U_{o}^{\prime}(I)-E U_{o o}^{\prime}(I)=\frac{f^{\prime}(I)}{\widehat{V}} \frac{1}{2} \frac{F^{2}}{(\widehat{V}+f(I))} \frac{m^{2}}{4(\beta-m)\left(\beta-\frac{m}{2}\right)^{2}}>0 .
$$


Therefore, investment and duration may be complement or substitute, depending on the comparison of the two terms. If they are complements, that is, $\frac{\partial^{2} U}{\partial I \partial d}\left(d^{*}, I^{*}\right) \geq 0$, then $\Lambda_{I}>0$ and $\Lambda_{d}>0$. If they are substitutes, the same inequalities hold as long as the functions $h(d)$ and $f(I)$ are sufficiently concave, which also imply that $\Delta>0$ ( $\Delta$ is always positive in any strict maximum).

Therefore, $\frac{\partial I^{*}}{\partial r}<0$ and $\frac{\partial d^{*}}{\partial r}<0$, as we aimed to prove.

\section{APPENDIX B: VARIABLe Definitions}

\begin{tabular}{|c|c|}
\hline Variables & Definitions \\
\hline CVC & $\begin{array}{l}\text { Indicator variable equal to } 1 \text { for CVC-backed start-ups } \\
\text { and } 0 \text { for IVC-backed start-ups }\end{array}$ \\
\hline CVC_Per & Percentage of investment by CVC funds in each start-up \\
\hline $\mathrm{IPO}$ & Indicator variable equal to 1 for an IPO exit and 0 for an aquisition exit \\
\hline Investment Amount & $\begin{array}{l}\text { Total investment amount at start-up level, measured by } \\
\text { disclosed equity amount (USD Million) summed over investment rounds }\end{array}$ \\
\hline Duration (Days) & $\begin{array}{l}\text { Difference in days between the exit date and the date at which } \\
\text { a start-up receives the first investment from VC funds }\end{array}$ \\
\hline Duration (Years) & Duration (Days) divided by 365 \\
\hline Investment Rounds & Number of investment rounds for a start-up \\
\hline Syndicate Size & Number of VC funds that invest in a start-up \\
\hline Syndicate Leader CVC & $\begin{array}{l}\text { Indicator variable equal to } 1 \text { if the } \mathrm{VC} \text { that provides the } \\
\text { maximum amount of investment is a CVC and } 0 \text { otherwise }\end{array}$ \\
\hline VC Fund Size & Average size (US\$ Million) of VC funds that finance the start-up \\
\hline CVC Strategic Re. & $\begin{array}{l}\text { Measure of CVC strategic competitors, } \\
\text { indicator variable of } 1 \text { if a CVC has the same 4-digit } \\
\text { SIC code as its start-up, and } 0 \text { otherwise }\end{array}$ \\
\hline VC Fund Age (Years) & Average fund age across all of the funds that invest in a start-up \\
\hline IVC Fund Age (Years) & Average fund age across IVC funds that invest in a start-up \\
\hline Industry $\mathrm{MB}$ & $\begin{array}{l}\text { Industry market-to-book value at the year } \\
\text { at which the first CVC fund invests }\end{array}$ \\
\hline 3-Month MSCI & MSCI return 0-3 months prior to the exit date \\
\hline Later Exit Stage & $\begin{array}{l}\text { Indicator variable equal to } 1 \text { if a start-up exits at expansion } \\
\text { or later stage and } 0 \text { otherwise }\end{array}$ \\
\hline Early Invest Stage & $\begin{array}{l}\text { Indicator variable equal to } 1 \text { if a start-up receives the first } \\
\text { investment at seed or early stage and } 0 \text { otherwise }\end{array}$ \\
\hline Industry 73 & $\begin{array}{l}\text { Indicator variable equal to } 1 \text { if a start-up is from the } \\
\text { Business Service industry and } 0 \text { otherwise }\end{array}$ \\
\hline Patent in Stock & $\begin{array}{l}\text { Total number of patents applied by start-ups } \\
\text { before they receive the first investment from VC funds }\end{array}$ \\
\hline 5-Year Avg WC & $\begin{array}{l}\text { Average working capital over } 5 \text { years before a certain year } \\
\text { in a certain industry }\end{array}$ \\
\hline 5-Year Avg Net CF & $\begin{array}{l}\text { Average net cash flow over } 5 \text { years before a certain year } \\
\text { in a certain industry }\end{array}$ \\
\hline Avg MSA CVC Inv/Total Inv & $\begin{array}{l}\text { Average CVC investment over total investment } \\
\text { amount in a year for an MSA }\end{array}$ \\
\hline Seed Stage & $\begin{array}{l}\text { Dummy variable equal to } 1 \text { if start-up is at the seed stage } \\
\text { when receiving the first investment and } 0 \text { otherwise }\end{array}$ \\
\hline Early Stage & $\begin{array}{l}\text { Dummy variable equal to } 1 \text { if start-up is at the early stage } \\
\text { when receiving the first investment and } 0 \text { otherwise }\end{array}$ \\
\hline Expansion Stage & $\begin{array}{l}\text { Dummy variable equal to } 1 \text { if start-up is at the expansion stage } \\
\text { when receiving the first investment and } 0 \text { otherwise }\end{array}$ \\
\hline
\end{tabular}




\section{REFERENCES}

Aghion, P., and P. Bolton, 1992, "An Incomplete Contracts Approach to Financial Contracting," The Review of Economic Studies, 59, 473-494.

Akerlof, G.A., 1970, “The Market for 'Lemons': Quality Uncertainty and the Market Mechanism," The Quarterly Journal of Economics, 84, 488-500.

Atanassov, J., 2013, “Do Hostile Takeovers Stifle Innovation? Evidence from Antitakeover Legislation and Corporate Patenting," Journal of Finance, 68, 1097-1131.

Basu, S., C.C. Phelps, and S. Kotha, 2011, "Towards Understanding Who Makes Corporate Venture Capital Investments and Why," Journal of Business Venturing, 26, 153-171.

Bayar, O. and T. Chemmanur, 2011, "IPOs versus Acquisitions and the Valuation Premium Puzzle: A Theory of Exit Choice by Entrepreneurs and Venture Capitalists." Journal of Financial and Quantitative Analysis, 46, 1755-1793.

- 2012, "What Drives the Valuation Premium in IPOs versus Acquisitions? An Empirical Analysis," Journal of Corporate Finance, 18, 451-475.

Bergemann, D., and U. Hege, 1998, "Venture Capital Financing, Moral Hazard, and Learning," Journal of Banking E Finance, 22, 703-735.

Brau, J.C., B. Francis, and N. Kohers, 2003, "The Choice of IPO versus Takeover: Empirical Evidence," Journal of Business, 76, 583-612.

Chemmanur, T.J. and E. Loutskina, 2008, “How Do Corporate Venture Capitalists Create Value for Entrepreneurial Firms?" Unpublished Working Paper, Boston College, Massachusetts.

Chemmanur, T., J. He, S. He, and D. Nandy, 2012, "The Exit Choices of Entrepreneurial Firms." Working Paper, Boston College.

Chemmanur, T.J., E. Loutskina, and X. Tian, 2014, "Corporate Venture Capital, Value Creation, and Innovation." The Review of Financial Studies, 27, 2434-2473.

Conti, A., M. Thursby, and F.T. Rothaermel, 2013, "Show Me the Right Stuff: Signals for High-Tech Startups," Journal of Economics \& Management Strategy, 22, 341Đ364.

Crain, N., 2013, "Career Concerns and Venture Capital," Working Paper, University of Texas at Austin.

Cumming, D.J., 2008, "Contracts and Exits in Venture Capital Finance," The Review of Financial Studies, 21, No. 5 .

- and J.G. MacIntosh, 2003, "Venture Capital Exits in Canada and the United States," The University of Torento Law Journal, 53, 101-200.

— and S.A. Johan, 2009, Venture Capital and Private Equity Contracting: An International Perspective, Academic Press.

Da Gbadji, L.G., B. Gailly, and A. Schwienbacher, 2011, "International Analysis of Venture Capital Programs of Large Corporations and Financial Institutions," Unpublished Working Paper, Université Catholique Louvain, Belgium.

Da Rin, M., T.F. Hellmann, and M. Puri, 2013, “A Survey of Venture Capital Research,” in M. Harris and R. Stulz, eds., Handbook of the Economics of Finance, Vol. 2. Amsterdam: North Holland.

De Bettignies, J.E., 2008, "Financing the Entrepreneurial Venture," Management Science, 54, 151-166.

Dushnitsky, G., and M.J. Lenox, 2006, "When Does Corporate Venture Capital Investment Create Firm Value?," Journal of Business Venturing, 21, 753-772.

— and Z. Shapira, 2010, “Entrepreneurial Finance Meets Organizational Reality: Comparing Investment Practices and Performance of Corporate and Independent Venture Capitalists," Strategic Management Journal, 31, 990-1017.

Felix, E., C. Pires, and M. Gulamhussenb, 2014, "The Exit Decision in the European Venture Capital Market," Quantitative Finance 14, 1115-1130.

Folta, T.B., 1998, "Governance and Uncertainty: The Trade-off between Administrative Control and Commitment," Strategic Management Journal 19, 1007-1028.

Gans, J.S., D.H. Hsu, and S. Stern, 2002, "When Does Start-up Innovation Spur the Gale of Creative Destruction?," RAND Journal of Economics, 33, 571-586.

— and S. Stern, 2003, "The Product Market and the Market for "Ideas": Commercialization Strategies for Technology Entrepreneurs," Research Policy, 32, 333-350.

Gompers, P.A., 1995, “Optimal Investment, Monitoring, and the Staging of Venture Capital," Journal of Finance, $50,1461-1489$.

- and J. Lerner, 2000, "The Determinants of Corporate Venture Capital Success: Organizational Structure, Incentives and Complementarities," in Randall, Morck, ed. Concentrated Corporate Ownership, Chicago: University of Chicago Press. 
Guo, B., 2010, "Essays on Economics of Organizations," Chapter 3, PhD Thesis, Universitat Autònoma de Barcelona, Barcelona.

Hall, B.H., A.B. Jaffe, and M. Trajtenberg, 2001, “The NBER Patent Citation Data File: Lessons, Insights and Methodological Tools," NBER Working Paper 8498.

Harrison, W.T., C.T. Horngren, C.W. Thomas, and T. Suwardy, 2011, Financial Accounting, Pearson, Singapore. Heckman, J., 1979, "Sample Selection Bias as a Specification Error," Econometrica 47, 153-161.

Hellmann, T.F., 2002, "A theory of strategic venture investing," Journal of Financial Economics, 64, $284-314$.

—, L. Lindsey, and M. Puri, 2008, "Building Relationships Early: Banks in Venture Capital," The Review of Financial Studies, 21, 513-541.

Hong, S., K. Serfes, and V. Thiele, 2013, The Market for Venture Capital: Entry, Competition and the Survival of Start-up Companies, Working Paper, Drexel University.

Ivanov, V.I. and F. Xie, 2010, “Do Corporate Venture Capitalists Add Value to Start-up Firms? Evidence from IPOs and Acquisitions of VC-backed Companies," Financial Management 39, 129-152.

Kaplan, S.N., and P. Strömberg, 2003, "Financial Contracting Meets the Real World: An Empirical Study of Venture Capital Contracts," Review of Economic Studies, 70, 281-315.

Lantza, J.S., J.M. Sahutb, and F. Teulonc, 2011, "What Is the Real Role of Corporate Venture Capital?," International Journal of Business, 16, 367-382.

Li, K., and N.R. Prabhala, 2007, "Self-selection Models in Corporate Finance," in Handbook of Corporate Finance: Empirical Corporate Finance, edited by B. E. Eckso. Amsterdam, The Netherlands: NorthHolland.

Macho-Stadler, I., and D. Pérez-Castrillo, 2010, "Incentives in University Technology Transfers," International Journal of Industrial Organization, 28, 362-367.

Maddala, G.S., 1983, “Limited Dependent and Qualitative Variables in Econometrics," Econometric Society Monographs No. 3, Cambridge University Press, Cambridge.

Manso, G., 2011, "Motivating Innovation," Journal of Finance, 66, 1823-1860.

Masulis, R.W., and R. Nahata, 2009, "Financial Contracting with Strategic Investors: Evidence from Corporate Venture Capital-Backed IPOs," Journal of Financial Intermediation, 18, 599-631.

Maula, M.V. and G.C. Murray, 2001, "Corporate Venture Capital and the Exercise of the Options to Acquire," R\&D Management, 27 November.

Meyer, T. and P.Y. Mathonet, 2005, Beyond the J Curve: Managing a Portfolio of Venture Capital and Private Equity Funds, John Wiley \& Sons, Ltd, The Atrium, Southern Gate, Chichester.

Muthoo, A., 2002. "The Economics of Bargaining," in UNESCO, ed. Knowledge for Sustainable Development: An Insight into the Encyclopedia of Life Support Systems. EOLSS Publishers Co. Ltd, Oxford, UK.

Osborne, M.J., and A. Rubinstein, 1990, Bargaining and Markets, New York: Academic Press.

Poulsen, A.B. and M. Stegemoller, 2008, "Moving from Private to Public Ownership: Selling out to Public Firms versus Initial Public Offerings," Financial Management, 37, 81-101.

Riyanto, Y.E., and A. Schwienbacher, 2006, "The Strategic Use of Corporate Venture Financing for Securing Demand," Journal of Banking \& Finance, 30, 2809-2833.

Sahaym, A., H.K. Steensma, and J.Q. Barden, 2010, “The Influence of R\&D Investment on the Use of Corporate Venture Capital: An Industry-Level Analysis," Journal of Business Venturing, 25, 376-388.

Schwienbacher, A., 2010, "Venture Capital Exits", in Venture Capital: Investment Strategies, Structures, and Policies, Wiley/Blackwell.

Siegel, R., E. Siegel, and I.C. MacMillan, 1988, “Corporate Venture Capitalists: Autonomy, Obstacles, and Performance," Journal of Business Venturing, 3, 233-247.

Smith, D.G., 2005, "The Exit Structure of Venture Capital," UCLA Law Review, 53, 315-356.

Stock, J.H., J.H. Wright, and M. Yogo, 2002, "A Survey of Weak Instruments and Weak Identification in Generalized Method of Moments," Journal of Business E Economics Statistics, 20, 518-529.

Sykes, H.B., 1990, “Corporate Venture Capital: Strategies for Success," Journal of Business Venturing, 5, $37-47$.

Toldra, A., 2010, "Venture Capital Syndication and Firm Entry: Theory and Evidence," Unpublished Working Paper, Universidad Carlos III de Madrid, Madrid.

Yost, M., and K. Devlin, 1993, "The State of Corporate Venturing," Venture Capital Journal, 33, 37-40.

Zingales, L., 1995, "Insider Ownership and the Decision to Go Public," Review of Economic Studies, 62, 425-448. 